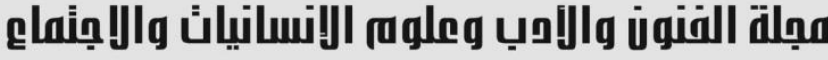

Journal of Arts, Literature, Humanities and Social Sciences www.jalhss.com

\title{
مدى إثباع رغبات طلاب الصفوف الثلاث الأولى كأحد ركائز الأمن النفسي من وجهة نظر أولياء أمور الطلاب في الأردن
}

عاصم عيسى الصرايرة البريد الأكتروني: asem.alsaraiyreh@gmail.com

مع ظهور وباء كورونا، أصبح التعليم عن بعد ضرورة حتمية لمو اصلة سيرورة العملية التعليمية و تجسيد أبحاث سنو ات مضت عن هذا النوع من التعليم على أرض الو اقع في الأردن، و لهذا كان الغرض من هذه الدراسة هو قياس مدى تلبية رغبات الطلاب النفسيه لدى طلاب الصفوف الثثلاث الأولى خلال التعليم عن بعد من وجهة نظر الأولياء في الأردن بحكم ما يصدر منهم من ردود أفعال و تفاعلات مع هذا النمط من التعليم. تم تطبيق هذه الدراسة في الفصل الدراسي الثاني من العام 2021م باستخدام المنهج التحليلي الوصفي حيث تكونت عينة

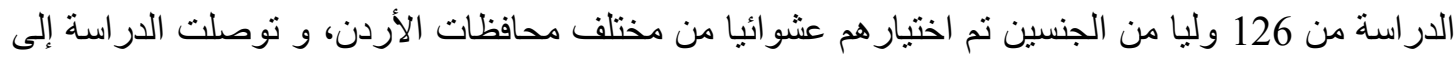

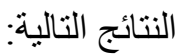
- أظهر تحليل النتائج المسجلة المتعلقة بالسؤال المطروح أن طلاب الصفوف الثلاث الأولى لم يشعروا بتلبية

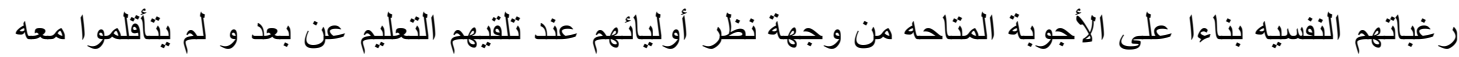

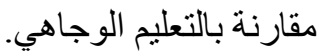
- تراوحت المتوسطات الحسابية ما بين 3,45 و 1,61 حيث جاءت العبارة (4) و التي تتص على " يحس طلاب الصفوف الثلاث الأولى بالملل من الحصص الدراسية خلال التعليم عن بعد مقارنة بالتعليم الوجاهي" في المرتبة الأولى بمنوسط حسابي 3,45 بينما جاءت العبارة (5) التي تتص على " يتفاعل طلاب الصفوف الثلاث الأولى مع معلميهم و زملائهم خلال حصص التعليم عن بعد أفضل مما يتفاعلون معهم داخل القسم في التعليم

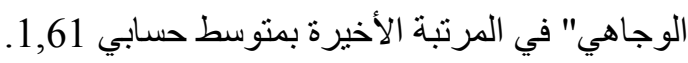

الكلمات المفتاحية: التعليم عن بعد، الرغبات التعليمية، رغبات الطلاب، الرغبات النفسية، الأمن النفسي. 
Journal of Arts, Literature, Humanities and Social Sciences www.jalhss.com

\title{
The extent to Which the Students' Psychological Desires of the First Three Grades Are Fulfilled from the Parents' Perspective in Jordan
}

\author{
Asem Eisa Alsaraiyreh \\ Ministry of Education - Jordan \\ Email: asem.alsaraiyreh@gmail.com
}

\begin{abstract}
With the appearance of the Corona Pandemic, online learning has become a necessity to continue education, and implement studies of the previous literature on this field in Jordan. That is to say, this study aims at exploring the extent to which the students' psychological desires are met for the first three grades in Jordan during online learning from the parents' perspectives. This is measured based on the responses given by the parents for a questionnaire conducted by the researcher. This study is carried out in the second semester/2021 using the descriptive analytical method where the study sample consists of 126 male and female parents who were selected randomly from different governments of Jordan. The results showed that the students of the first three grades do not fulfill their psychological desire, compared with face- to- face learning, based on the responses provided by the parents and that they do not adapt to it as the case with the online learning. In addition, the arithmetic averages ranged between 3.45 and 1.61 as statement (4) "students of the first three grades feel bored of lessons occurring online compared with face- to- face learning" comes in the first place with an arithmetic average of 3.45, while the statement "students of the first three grades interact with their teachers and colleagues in online learning sessions better than they do with them in face- to- face learning" comes in the last place with an average of 1.61 .
\end{abstract}

Keywords: online learning, educational desires, psychological desires, psychological security. 


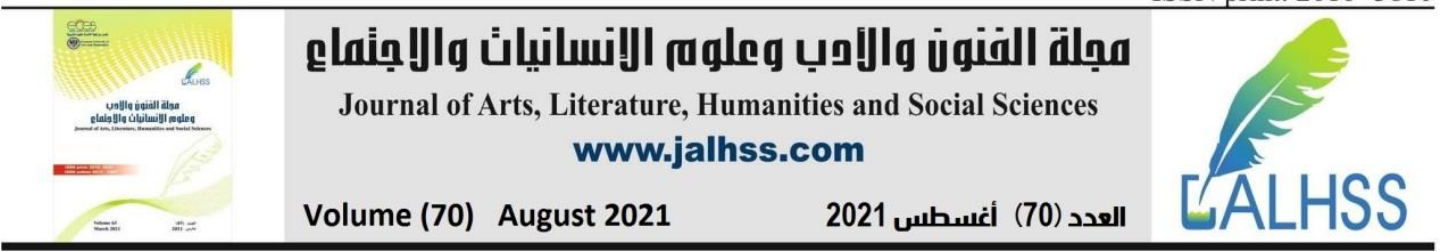

مقدمة.

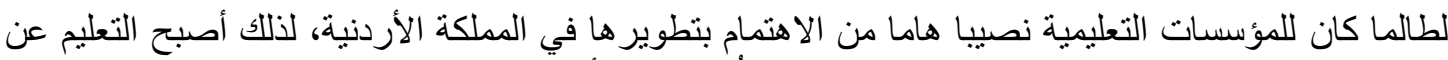

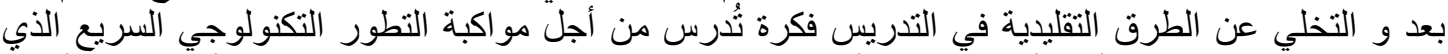

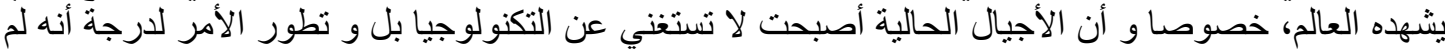

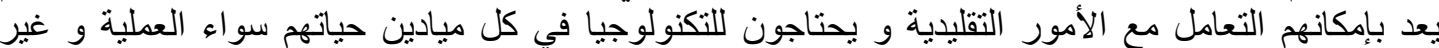

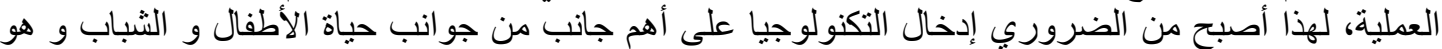

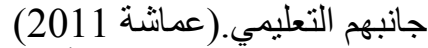

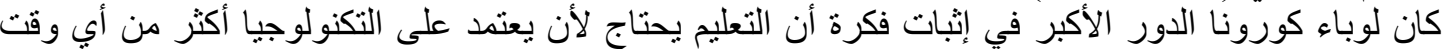

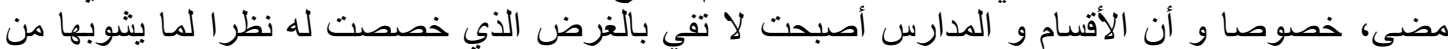

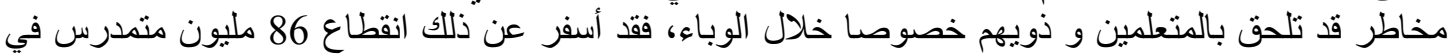

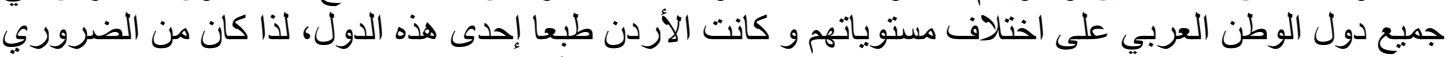

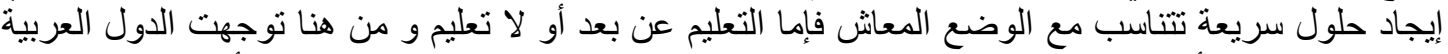

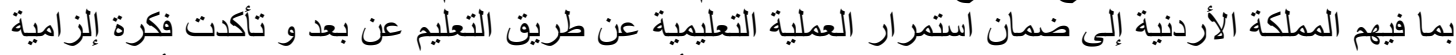
ربط التعليم بالتكنولوجيا الحديثة في جميع المستويات من أجل تسهيل العملية التعلمية. (منظمة الأمم المتحدة.

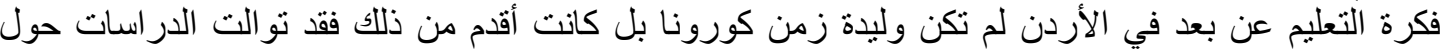

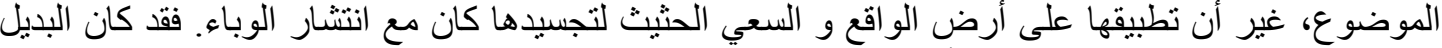

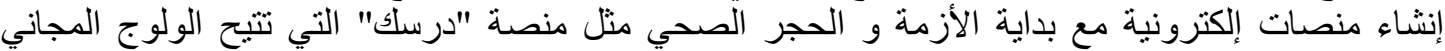

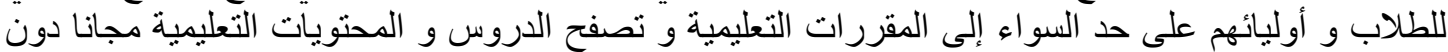

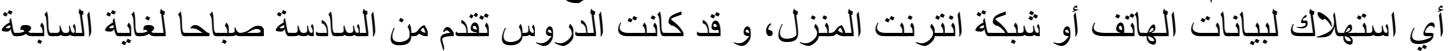

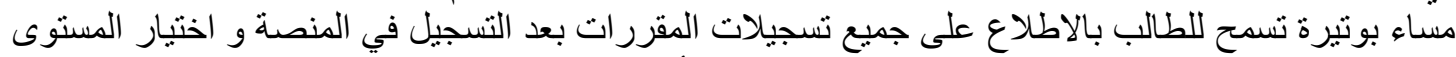
الدراسي الذي ينتمي إليه الطالب. (وزارة التربية و التعليم الأردنية. 2020)

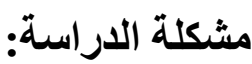

لا يختلف اثنان على أهمية التعليم و مكانته في الخطط التنموية لأي بلد، لذا عمدت الأردن إلى البحت البحث عن أحسن

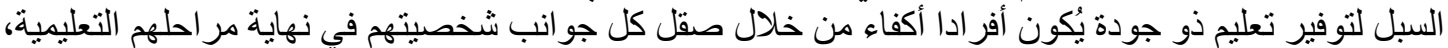

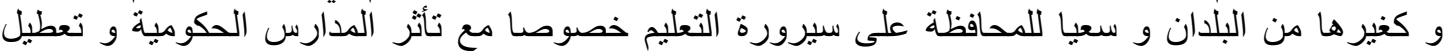
التعليم فيها خلال جائحة كورونا، تم اعتماد التعليم عن بعد لكل المراحل التعليمية بما فيها الصفير الصفوف الثلاثلاث

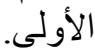

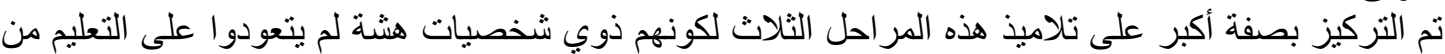

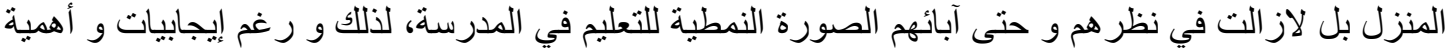

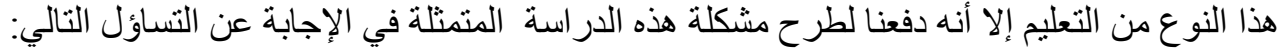

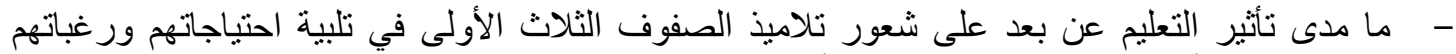

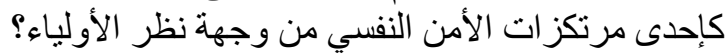

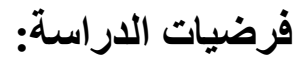

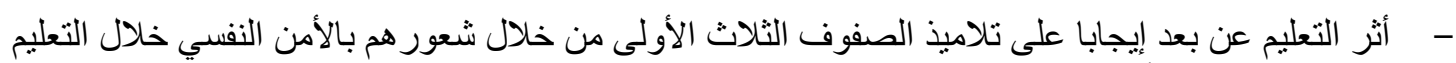

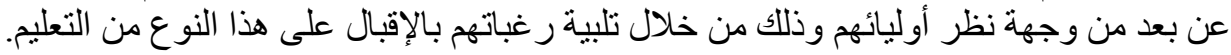

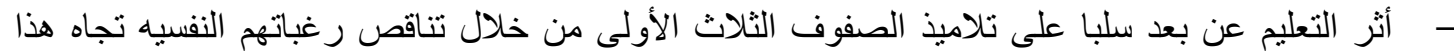
النوع من التعليم من وجهة نظر أوليائهر. 


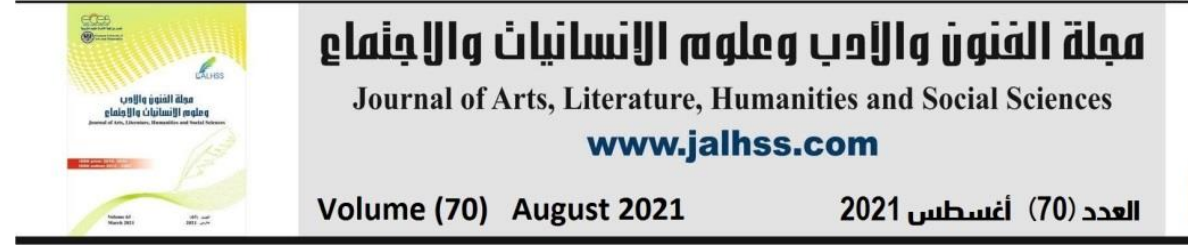

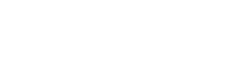

\section{(20)}

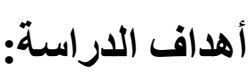

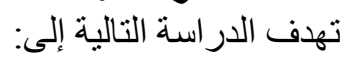

- ت تحديد مدى إثباع الرغبات و الإحتياجات النفسيه لطلاب الصفوف الثناث الأولى بالتعليم عن بعد من وجهة نظر أوليائهم. - - مديد موقف و اتجاه أولياء التلاميذ بخصوص التعليم عن بعد لتلاميذ الصفوف الثلاث الأولى.

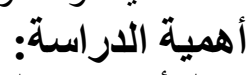
تتمثل أهمية هذه الدراسة فيما يلي:

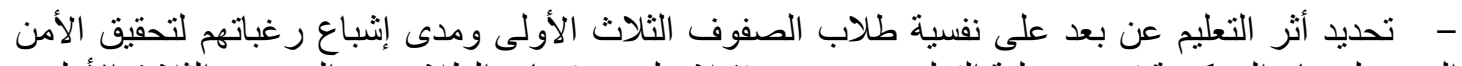

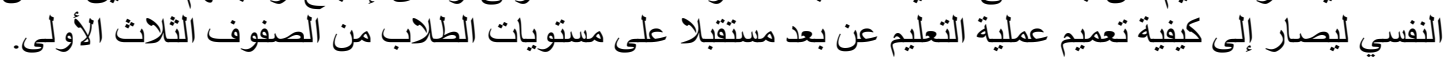

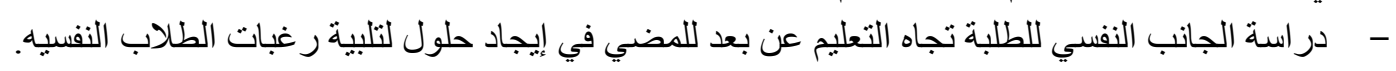

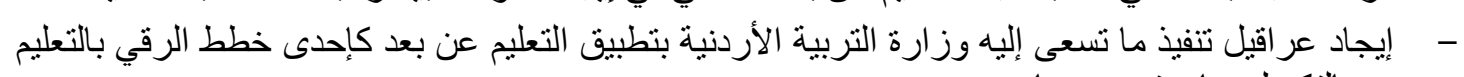
و دمجه بالتكنولوجيا و تصنيذ تصحيحها. حدود الاراسة: مدانة

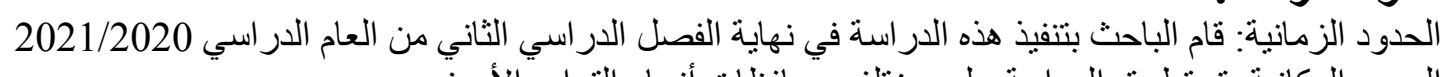

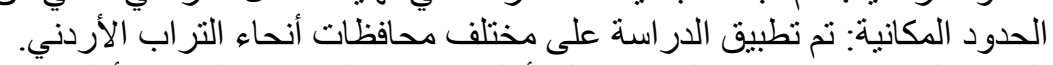

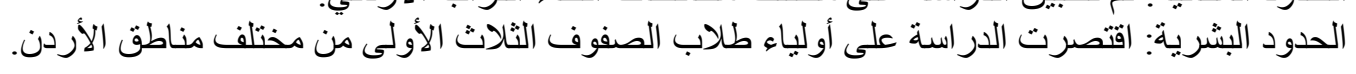

\section{مصطلحات الاراسة و تعريفاتها:}

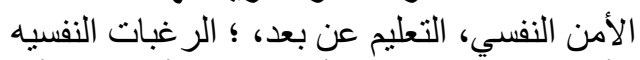

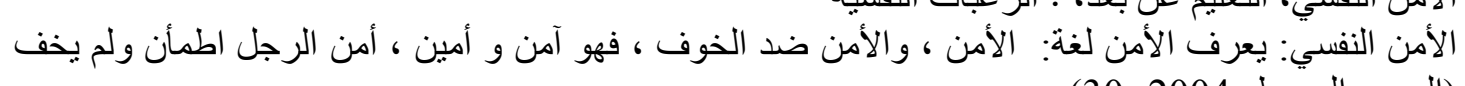

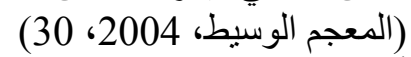
أما اصطلاحا: فقد تعددت التعاريف باختلاف الباحثين:

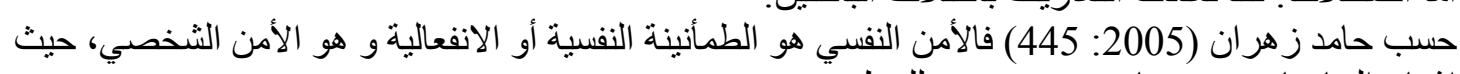

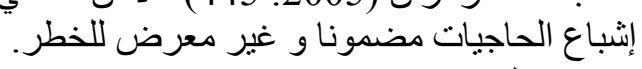

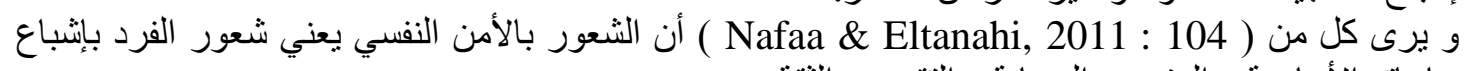

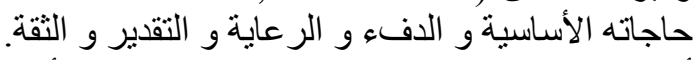

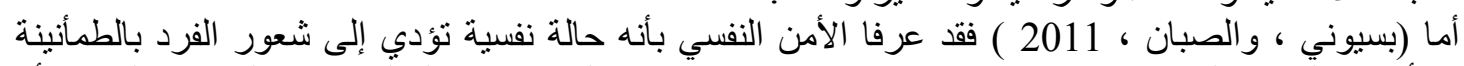

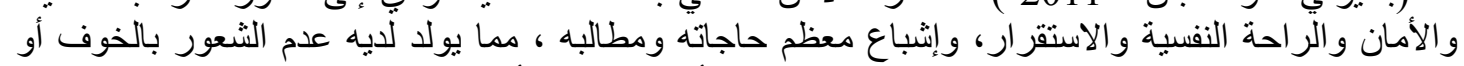

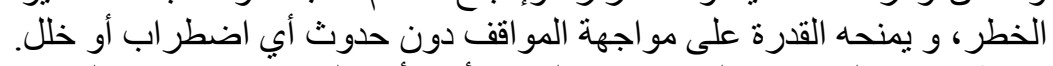

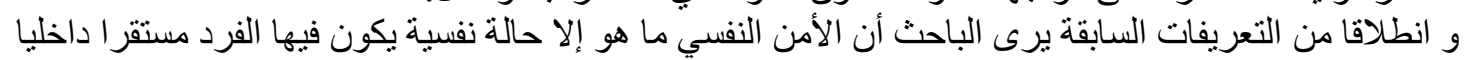

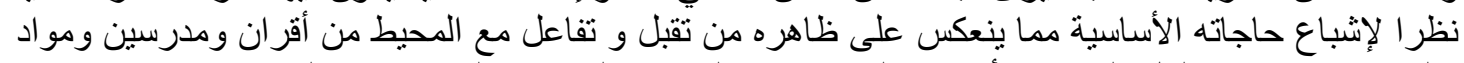

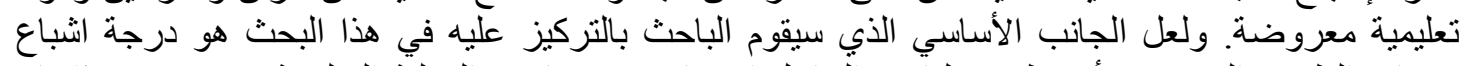

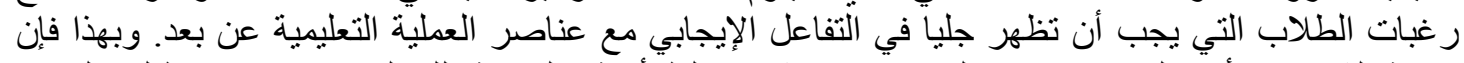

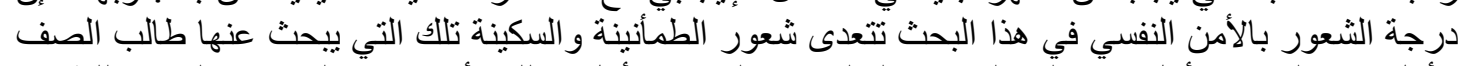

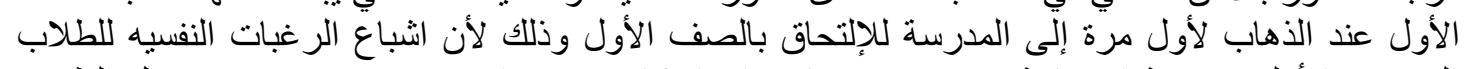

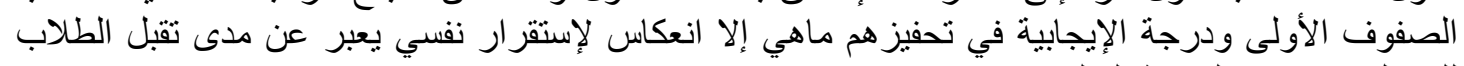

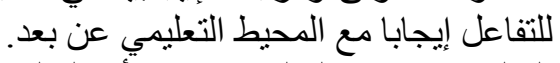

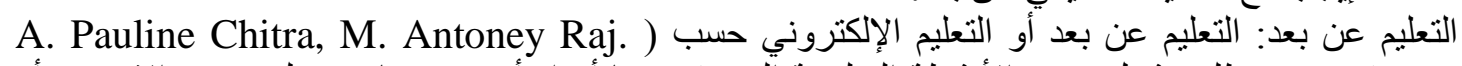

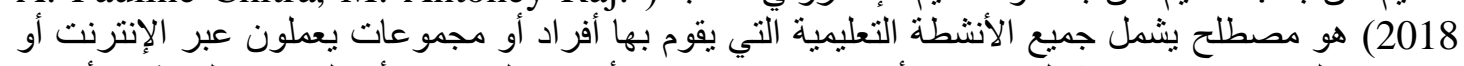

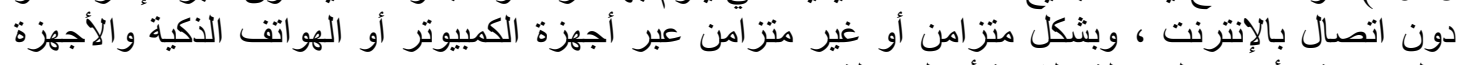

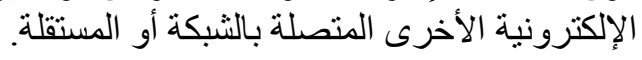




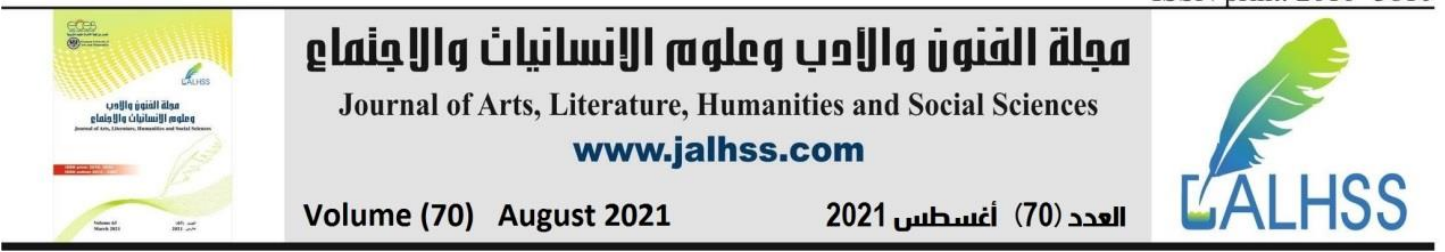

أما (Indira Dhull, Sakshi. 2017) فقد عرفا التعليم عن بعد بأنه التعلم عبر الإنترنت الذي يشمل مجموعة الإنة

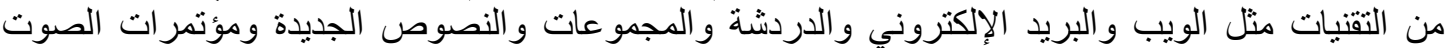

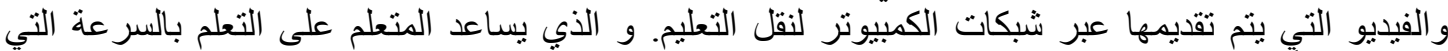

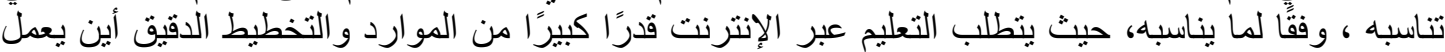

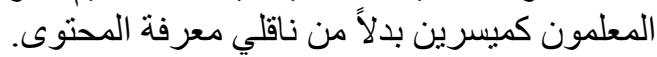

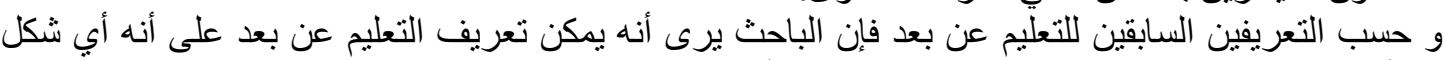

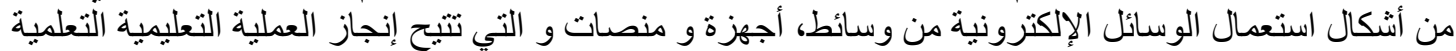
بغض النظر عن الظروف المحيطة نظر الكونه يسهل هذه العانطي العملية من خلال عدم التنقل.

الإطار النظري و الاراسات السابقة:

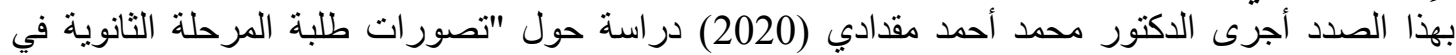

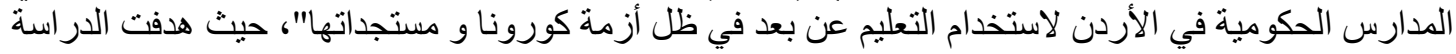

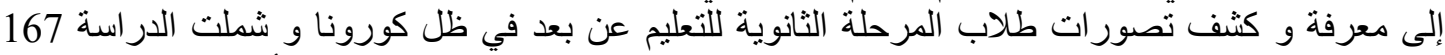

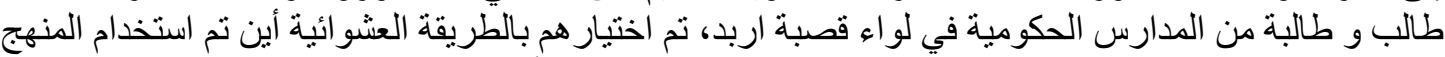

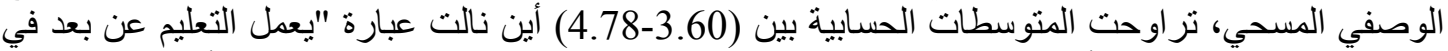

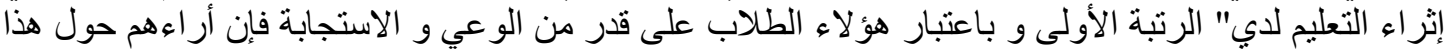

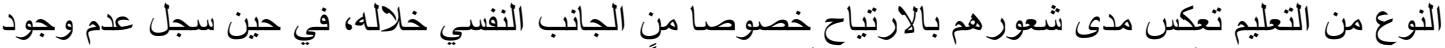

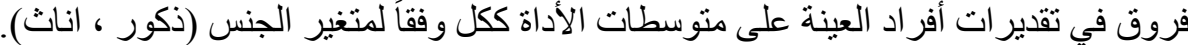

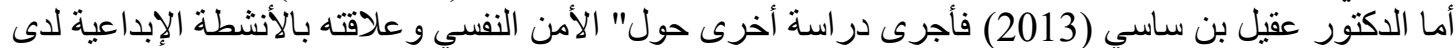

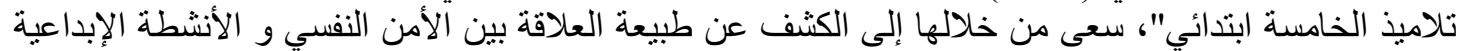

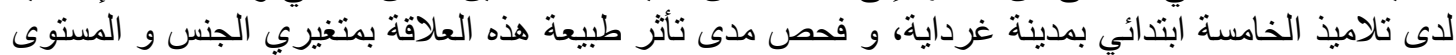

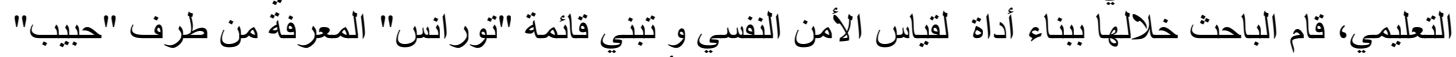

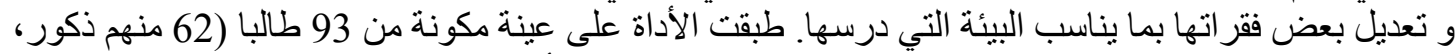

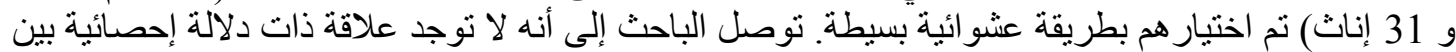

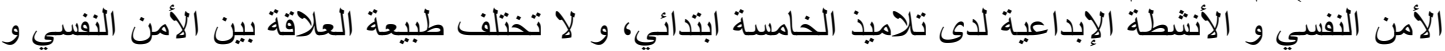

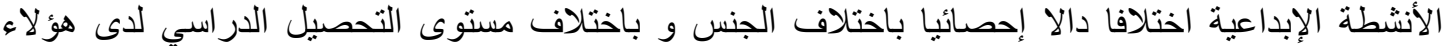

أما دراسة Andi Wahyu Irawan, Dwisona, Mardi Lestari (2020)، فقد عمدت إلى دراسة الأمن

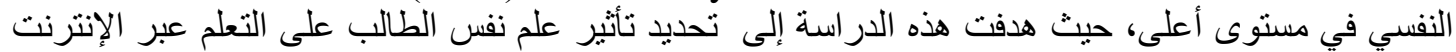

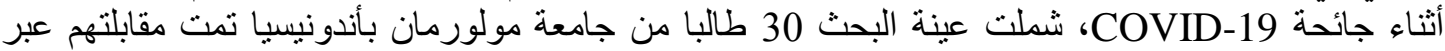

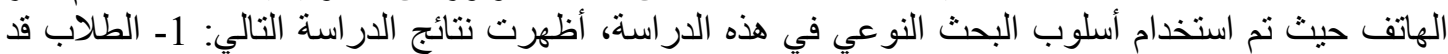

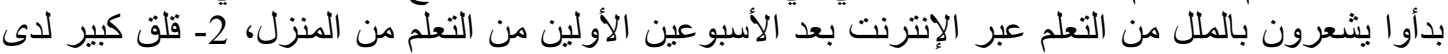

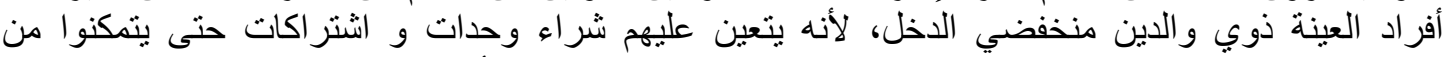

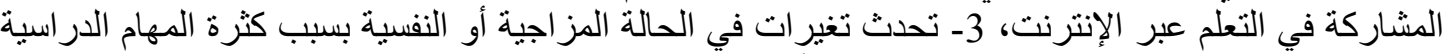

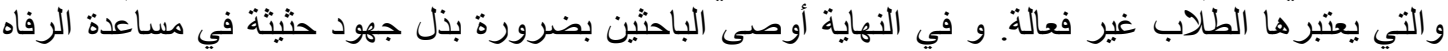

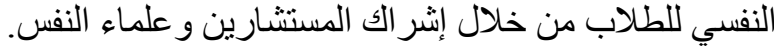

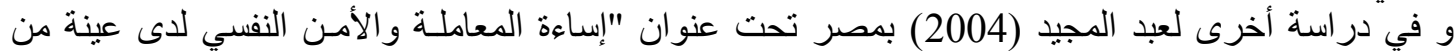
تلاميذ المدرسة الابتدائية". هدفت الدراسة إلى العلاقة بين إساءة المعاملة والأمن النفسي لدى عينة من تلاميذ لألئ المدارس الابتدائية الحكوميـة الابتة

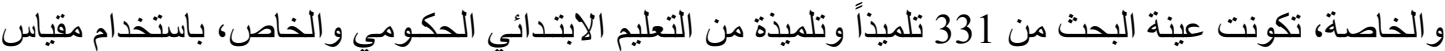

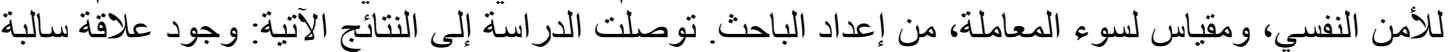

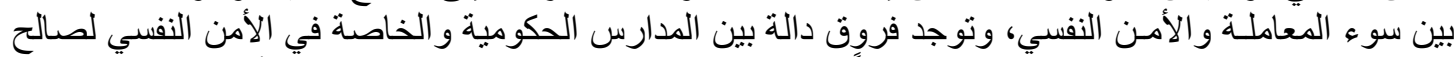

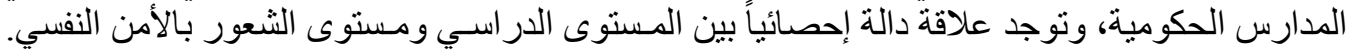




\begin{tabular}{|c|c|c|c|}
\hline 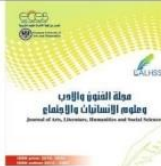 & 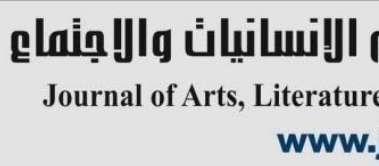 & $\begin{array}{l}\text { illg ưgill älng } \\
\text { ies and Social Sciences } \\
\text { om }\end{array}$ & \\
\hline$=$ & Volume (70) August 2021 & العدد (70) أغسطس 2021 & \\
\hline
\end{tabular}

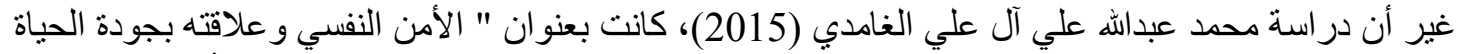

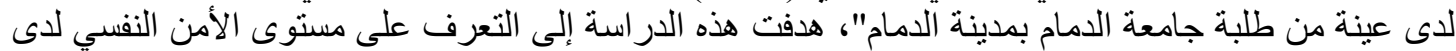

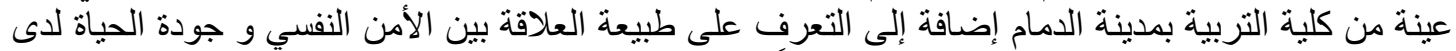

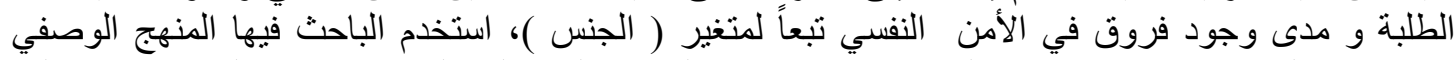

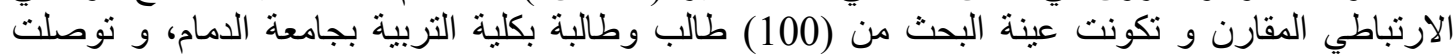

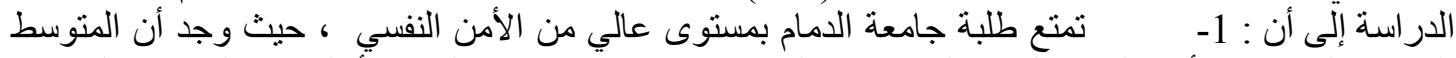

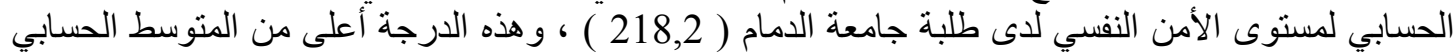

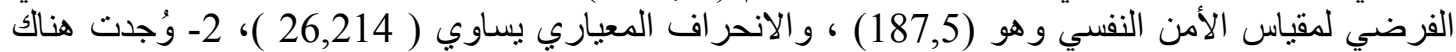

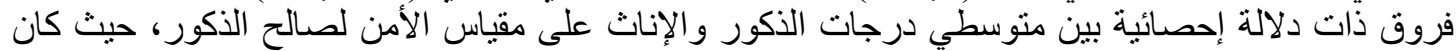

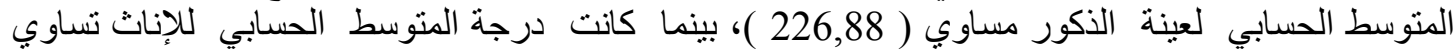
(209,52) ، وكانت درجة (ت ) مساوية ل) (3,494) للذكور و الإناث، 3.

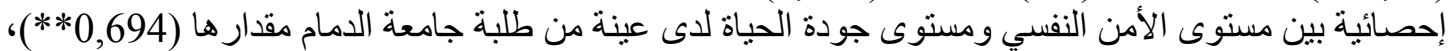
وذللك عند مستوى دلالة 0,01.

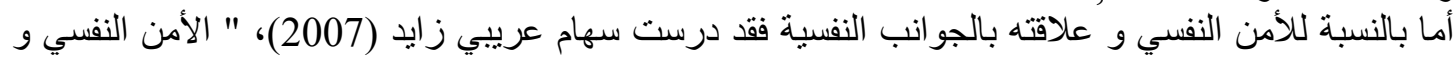

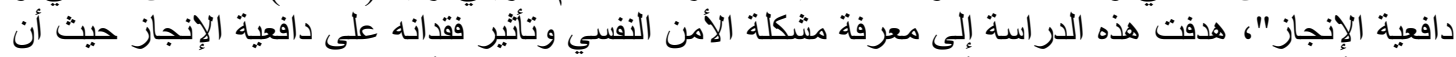

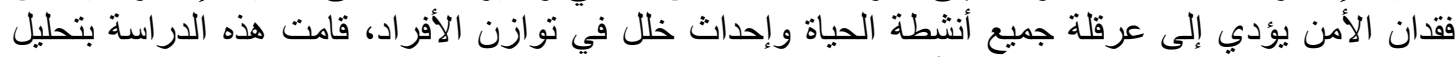

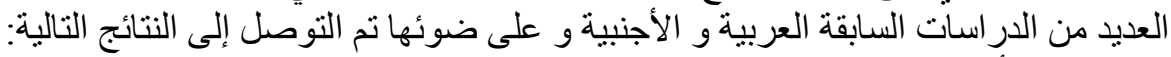

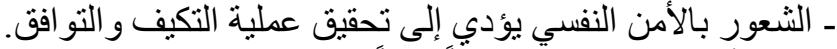

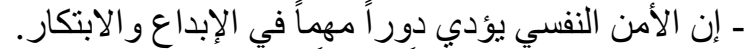
ـ ـ الأمن النفسي يعد شرطاً أساسياً لدافعية الانجاز وئ وعدم الثعور به يؤدي إلى الخفاض في مستوى الإنجاز.

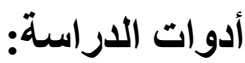

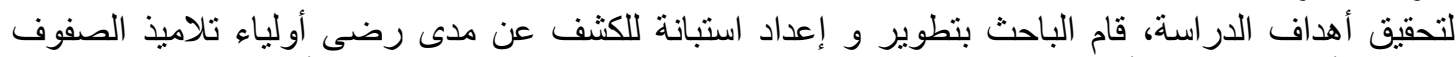

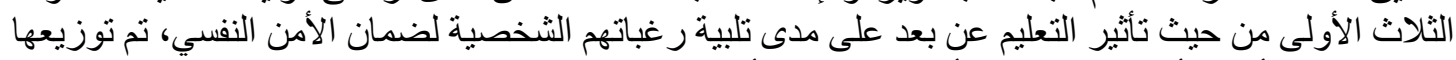

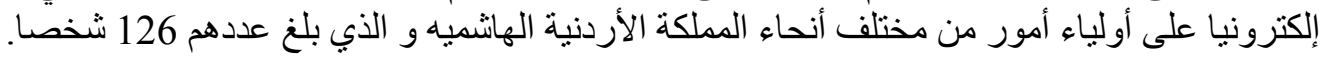

\section{منهج الاراسة: الباحة استخدم الباحث المنهج الوصفي المسحي و ذلك نظر الملائمته لأهداف الدراسة و أغر اضها.} مجتمع الاراسة و عينتها:

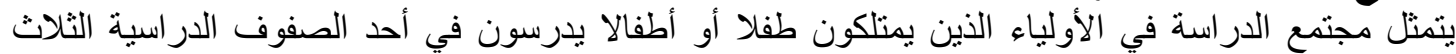

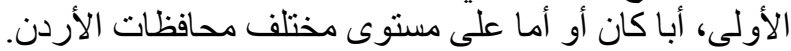

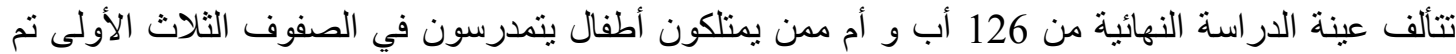
اختيار هم عشو ائيا من مختلف محافظات الأردن من خلال إرسال الاستبيان عبر البريد الإلكتروني.

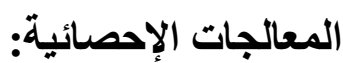
قام الباحثث بحساب الإحصنوسة: المسات الحسابية والانحر افات المعيارية لإجابات عينة الدراسة لكل سؤال من أسئلة

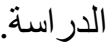
المعيار الإحصائي: الميكان

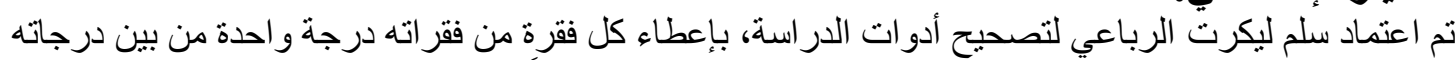

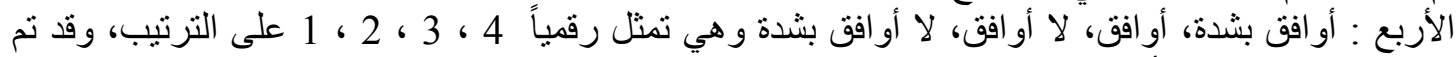

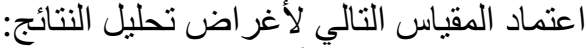
من 1.00 - 1.75 لا أو افق بشدة لافي من 1.76- 1.00 - 2.51 لا أو افق 


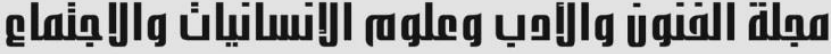

Journal of Arts, Literature, Humanities and Social Sciences www.jalhss.com

من 2.52 - 3.27 أو افق من 2.28 - 4.03 أو افق بشدة و هكذا وقد تم احتساب المقياس من خلال استخدام المعادلة التالية: (الحد الأعلى للمقياس ( 4 ) - الحد الأدنى للمقياس (1) ) ) / عدد الفئات المطلوبة (4)

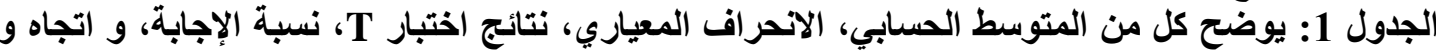

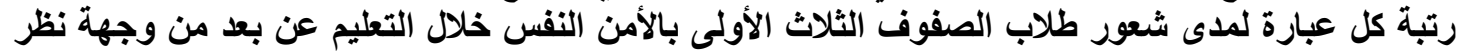

نتائج الدراسة و مناقشتها: عرض النتائج : الاولياء.

\begin{tabular}{|c|c|c|c|c|c|c|c|c|c|c|c|}
\hline رالعبارة & التجينة & النسبة & اختبار T & الانحر اف المعياري & الحسابي & بشد أو افق & أو الق & أو افق & بشّدة & رقبارة & العبارة \\
\hline 7 & بأو الَّ & $\% 42,5$ & $-9,16$ & 0,98 & 1,70 & 72 & 33 & 8 & 13 & 1 & 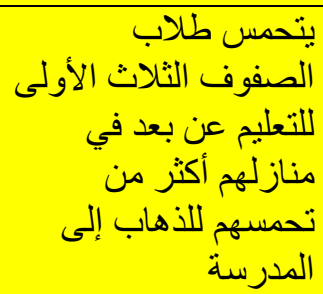 \\
\hline 8 & بأو افت & $\% 42,5$ & $-9,55$ & 0,94 & 1,70 & 67 & 40 & 8 & 11 & 2 & 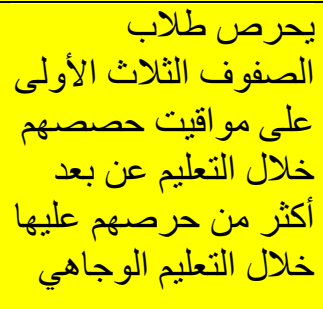 \\
\hline 2 & أو اقق & $\% 81$ & 9,23 & 0,9 & 3,24 & 7 & 17 & 41 & 61 & 3 & 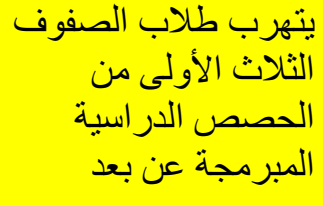 \\
\hline 1 & بشّدة أو افق & $\begin{array}{r}86,25 \\
\%\end{array}$ & 13,33 & 0,8 & 3,45 & 4 & 11 & 35 & 76 & 4 & 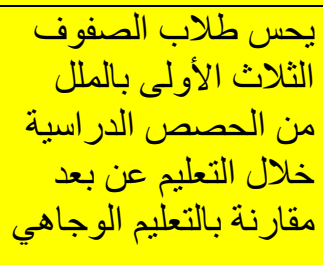 \\
\hline 10 & بأو افق & $\begin{array}{r}40,25 \\
\%\end{array}$ & $-11,35$ & 0,88 & 1,61 & 73 & 38 & 6 & 9 & 5 & 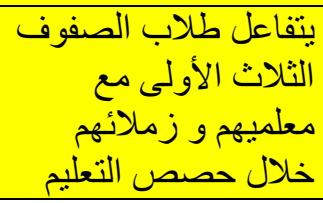 \\
\hline
\end{tabular}




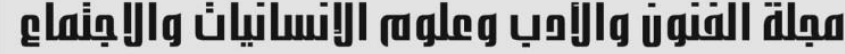

Journal of Arts, Literature, Humanities and Social Sciences www.jalhss.com

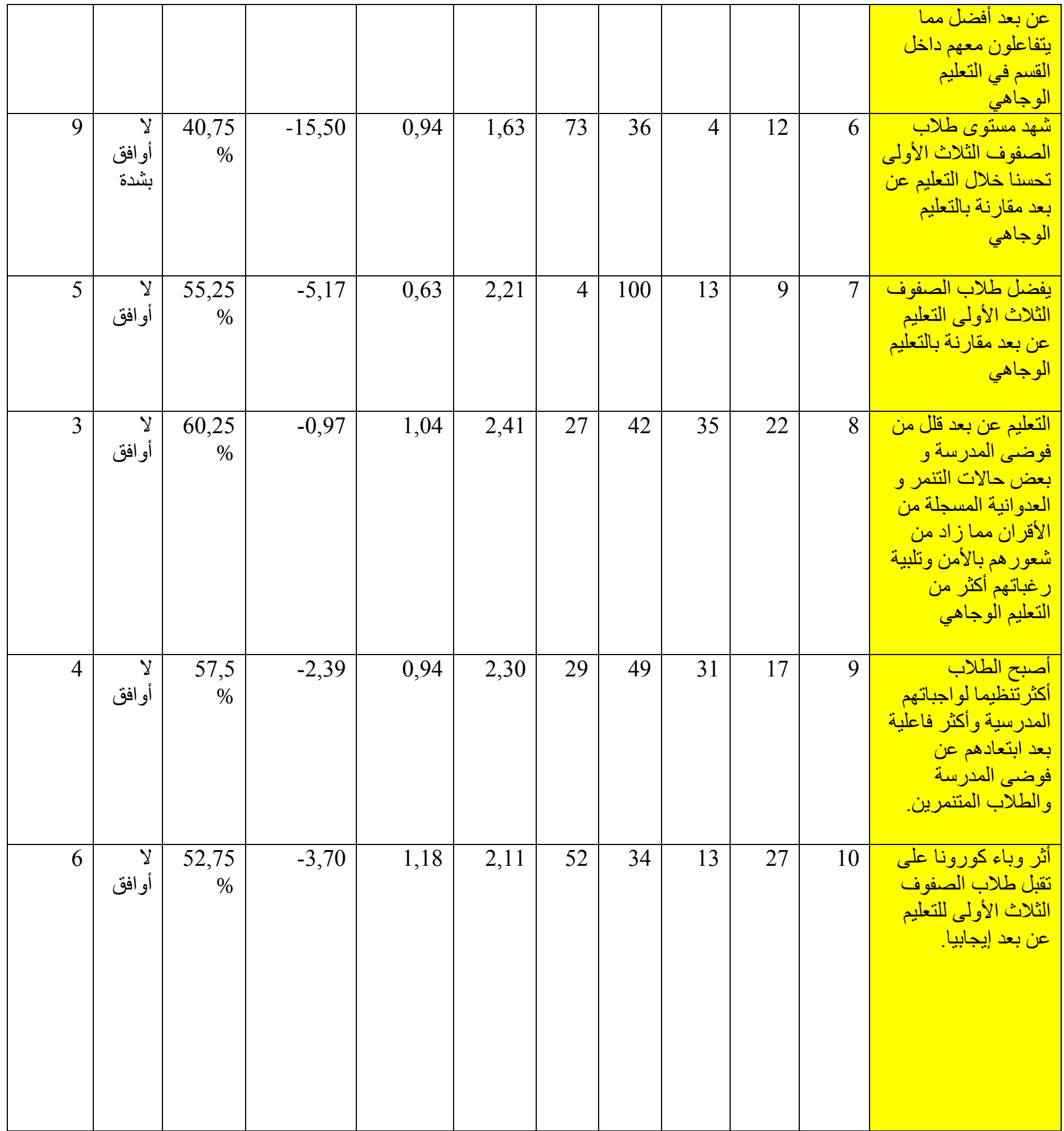




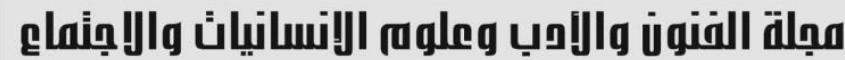

Journal of Arts, Literature, Humanities and Social Sciences www.jalhss.com

$=\quad$ Volume (70) August $2021 \quad$ العدد (70)

تبين الأعمدة البيانية الموضحة في الثكل 1 أن استجابة لا أو افق بشدة بالنسبة للعبارة الأولى قد نالت أغلى نسبة.

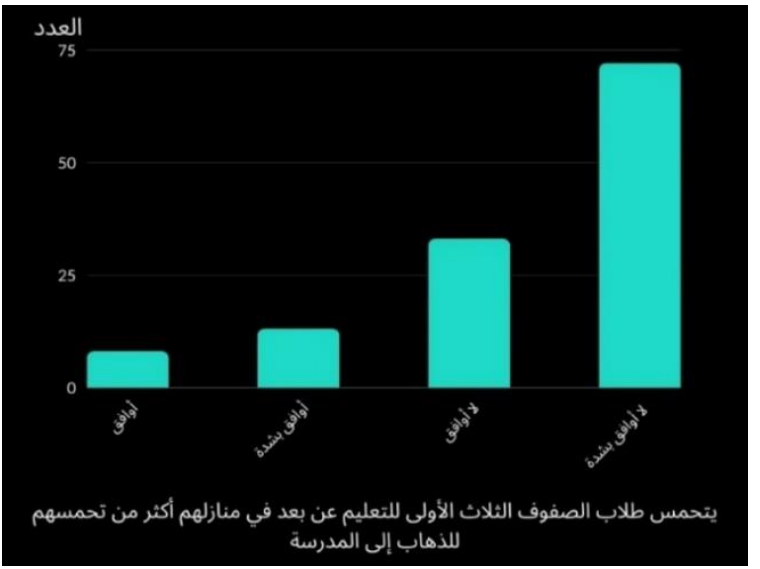

الثكل1: يمثل رسم بياني لنتائج استجابات العبارة 1 من الاستبيان

تبين الأعمدة البيانية الموضحة في الثكل 2 أن استجابة لا أو افق بشدة بالنسبة للعبارة الثانية سجلت أعلى نسبة.

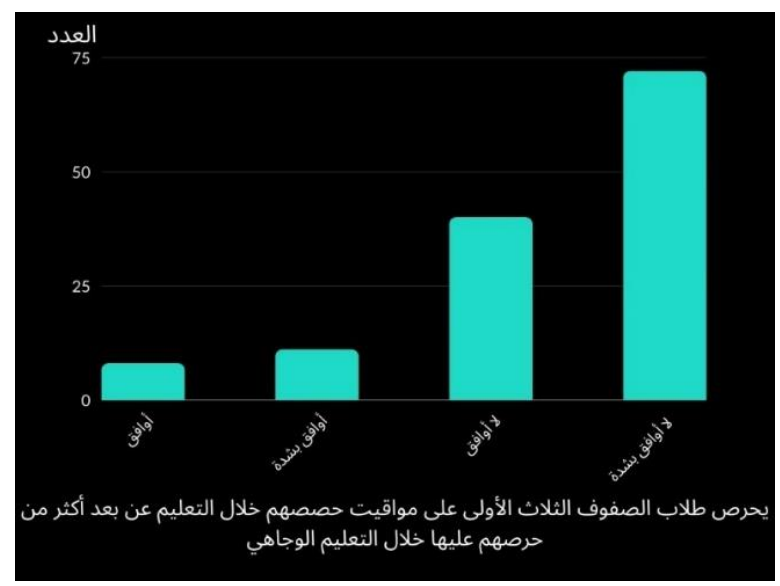

الثكل2: يمثل رسم بياني لنتائج استجابات العبارة 2 من الاستبيان 


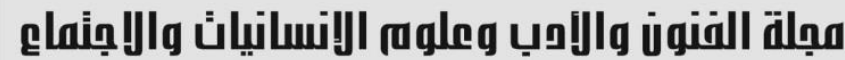

Journal of Arts, Literature, Humanities and Social Sciences www.jalhss.com

$=\quad$ Volume (70) August $2021 \quad 2021$ أغسط 20

تبين الأعمدة البيانية الموضحة في الثنكل 3 أن استجابة أو افق بشدة بالنسبة للعبارة الثالثة سجلت أعلى نسبة.

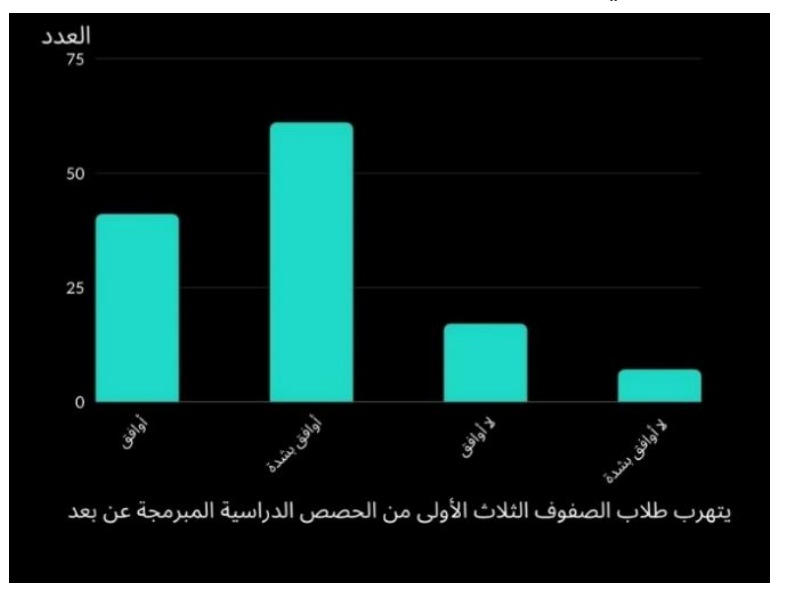

الثكل 3: يمثل رسم بياني لنتائج استجابات العبارة 3 من الاستبيان

تبين الأعمدة البيانية الموضحة في الثكل 4 أن استجابة أو افق بشدة بالنسبة للعبارة الر ابعة سجلت أعلى نسبة.

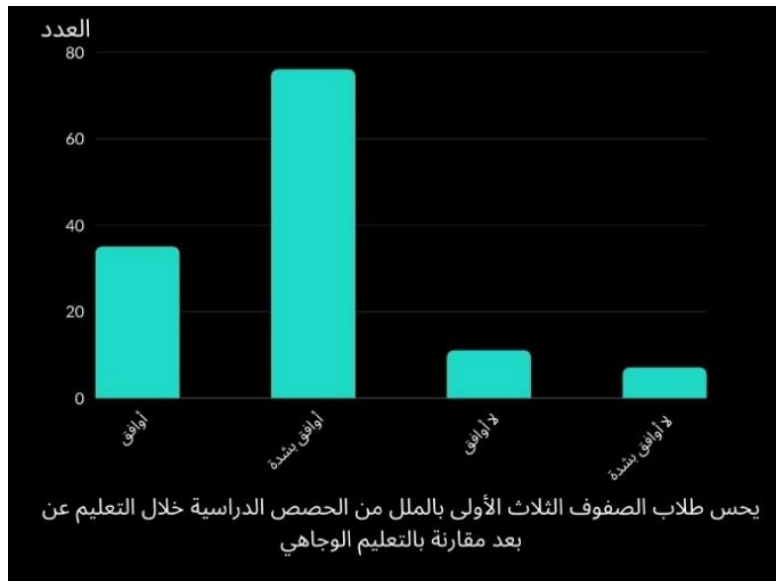

الثكل 4: يمثل رسم بياني لنتائج استجابات العبارة 4 من الاستبيان 


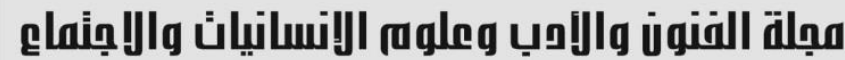

Journal of Arts, Literature, Humanities and Social Sciences www.jalhss.com

$=\quad$ Volume (70) August $2021 \quad 2021$ أغساس (70)

تبين الأعمدة البيانية الموضحة في الثكل 5 أن استجابة لا أوافق بالنسبة للعبارة الخامسة سجلت أعلى نسبة.

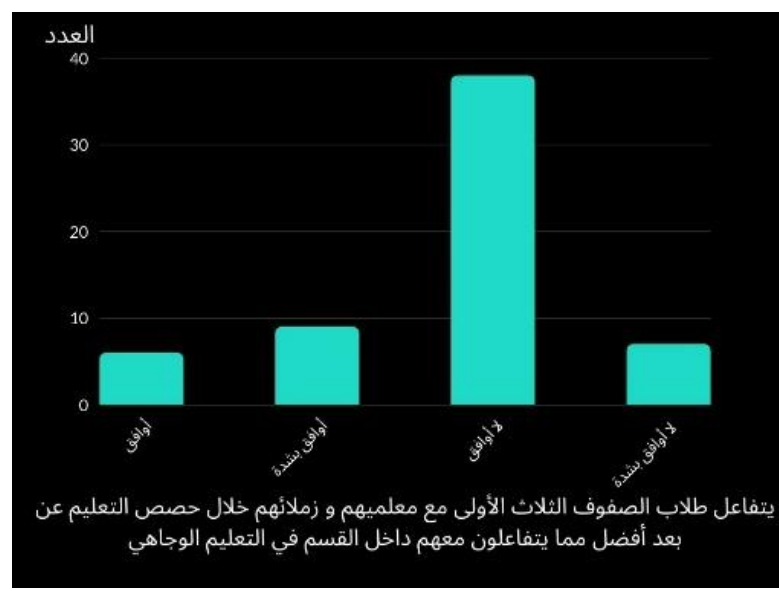

الشكل 5: يمثل رسم بياني لنتائج استجابات العبارة 5 من الاستبيان

تبين الأعمدة البيانية الموضحة في الثكل 2 أن استجابة لا أو افق بشدة بالنسبة للعبارة الثانية سجلت أعلى نسبة.

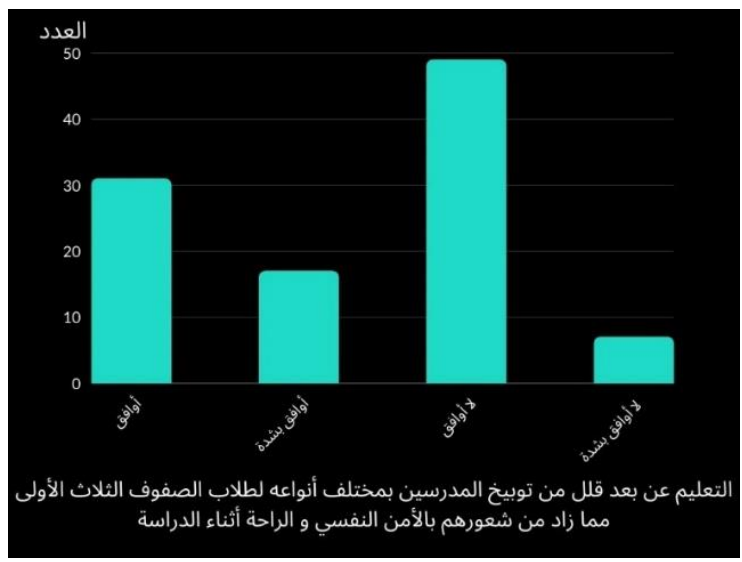

الثكل 6: يمثل رسم بياني لنتائج استجابات العبارة 6 من الاستبيان 


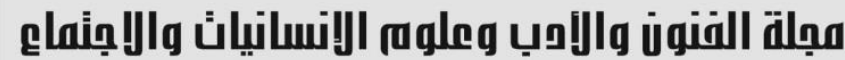

Journal of Arts, Literature, Humanities and Social Sciences www.jalhss.com

تبين الأعمدة البيانية الموضحة في الشكل7 أن استجابة لا أوافق بالنسبة للعبارة السابعة سجلت أعلى نسبة.

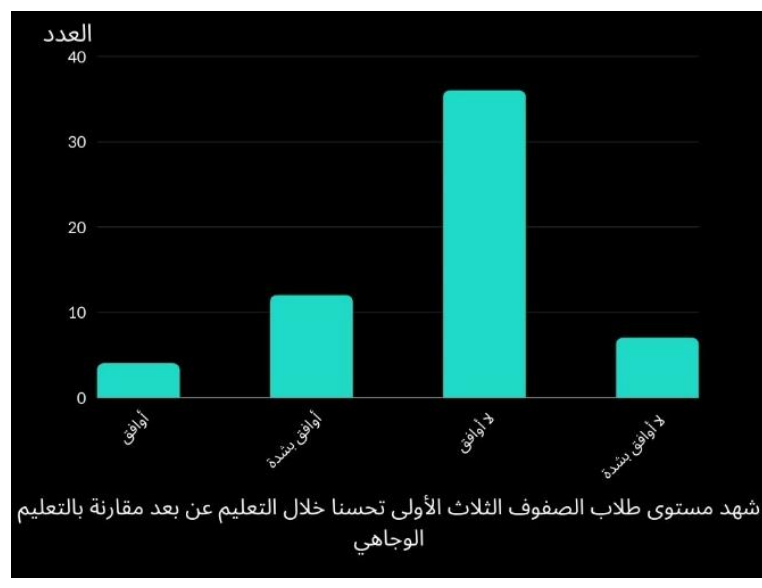

الشكل 7: يمثل رسم بياني لنتائج استجابات العبارة 7 من الاستبيان

تبين الأعمدة البيانية الموضحة في الثكل 8 أن استجابة لا أو افق بالنسبة للعبارة الثامنة سجلت أعلى نسبة.

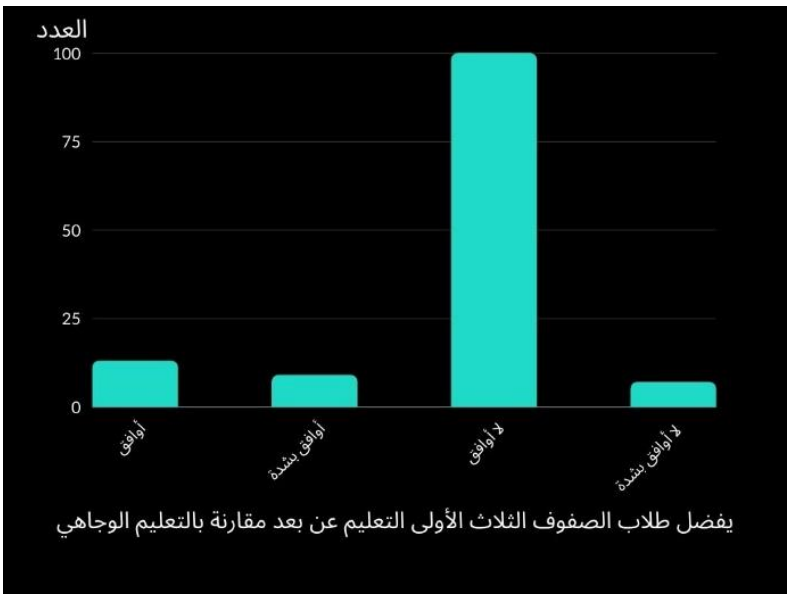

الثكل 8: يمثل رسم بياني لنتائج استجابات العبارة 8 من الاستبيان 


\begin{tabular}{|c|c|c|c|}
\hline 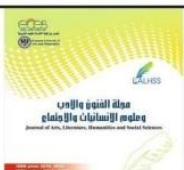 & 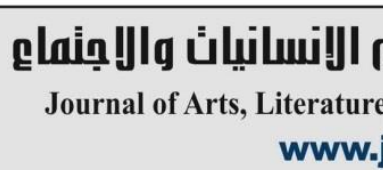 & 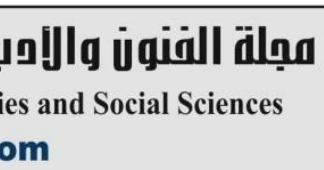 & \\
\hline$=\quad=$ & Volume (70) August 2021 & العدد (70) أغسطس 2021 & \\
\hline
\end{tabular}

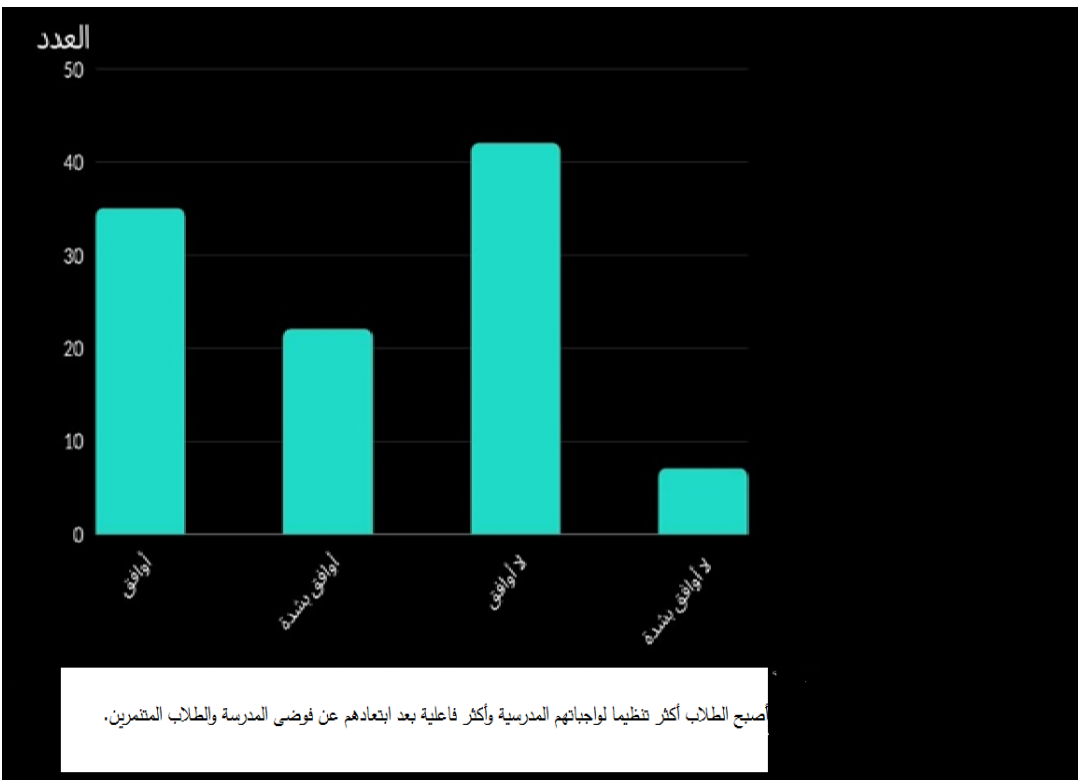

الشكل 9: يمثل رسم بياني لنتائج استجابات العبارة 9 من الاستبيان

تبين الأعمدة البيانية الموضحة في الثكل 9 أن أستجابة لا أو افق بالنسبة للعبارة التاسعة سجلت الأبنان أعلى نسبة.

تبين الأعمدة البيانية الموضحة في الثكل 10 أن استجابة لا أو افق بشدة بالنسبة للعبارة العانشرة سجلت أعلى

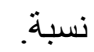

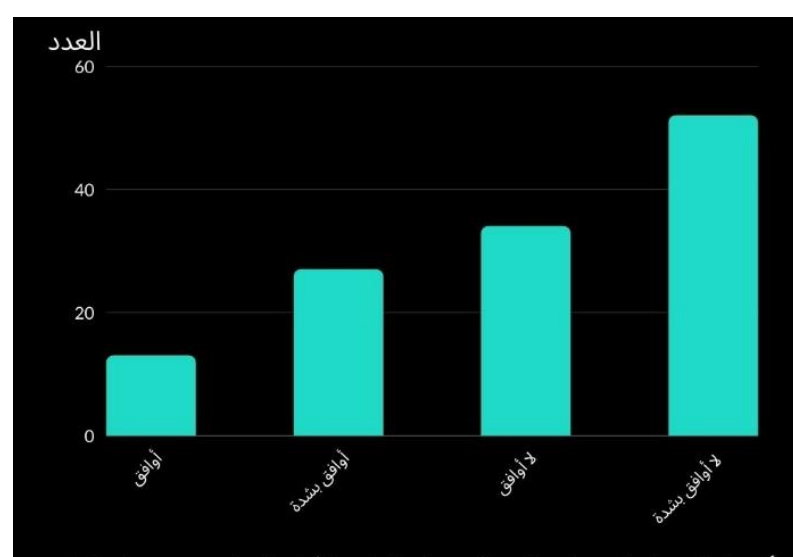

أثر وباء كورونا على تقبل طلاب الصفوف الثلاث الأولى للتعليم عن بعد إيجابيا

الثكل 10: يمثل رسم بياني لنتائج استجابات العبارة 10 من الاستبيان 


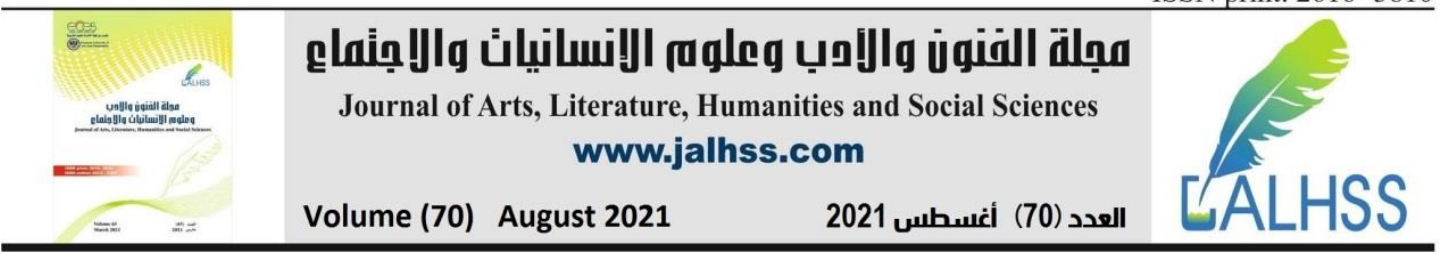

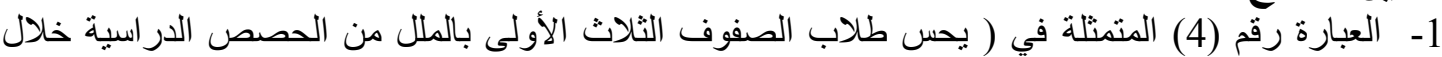

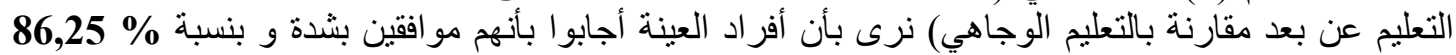

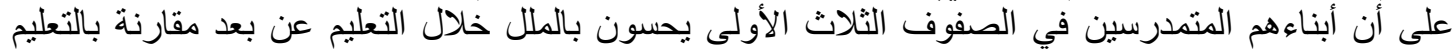

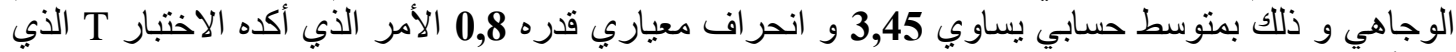

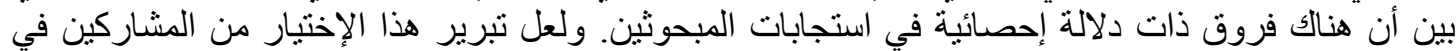

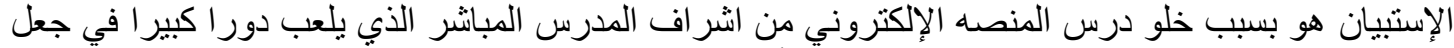

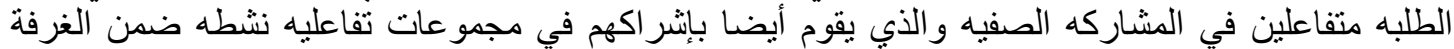
الصفيه التقليديه. 2- العبارة رقم (3) المتمثلة في (يتهرب طلاب الصفوف الثناث الأولى من الحصص الدر اسية المبرمجة عن

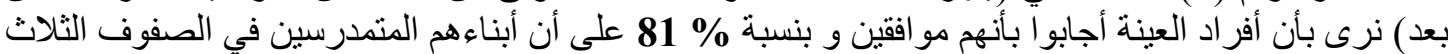

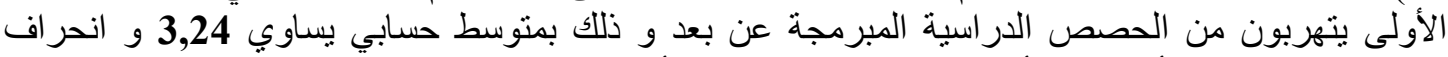
معياري قدره 0,9 الأمر الذي أكده الاختبار T الذي بين أن هنالك فروق ذات دلالة إحصبائية في استجابات

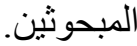

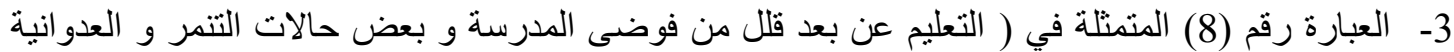

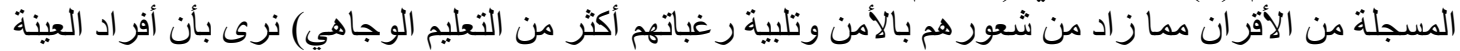

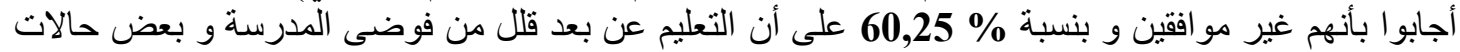

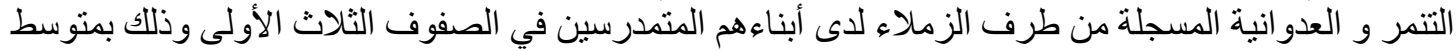

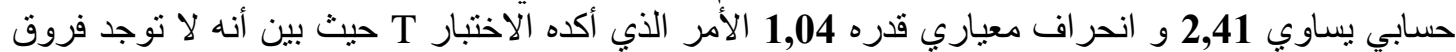
ذات دلالة إحصائية في استجابات المبحوثين.

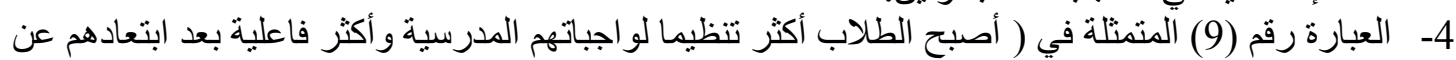

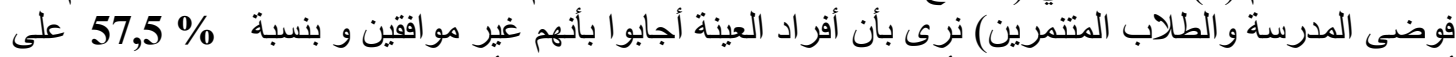

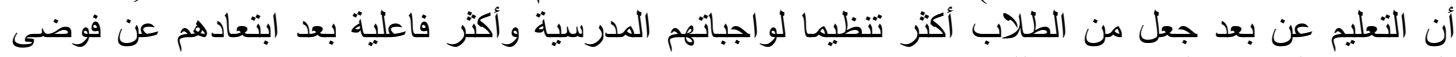

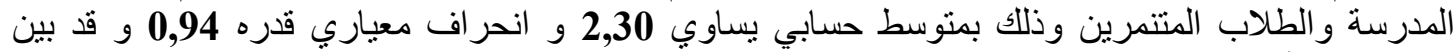

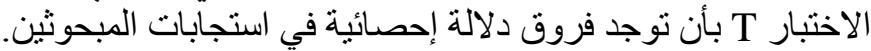

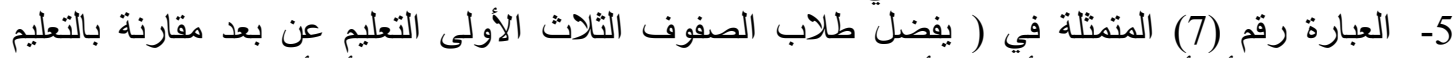

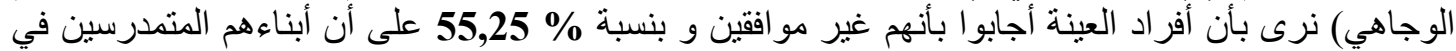

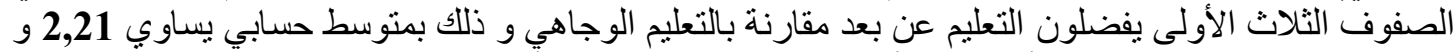
انحر اف معياري قدره 0,63 الأمر الذي أكده الاختبار T الذي بين أنَه نوجد فروق ذات دلالة إلحصائية في

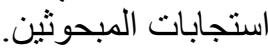

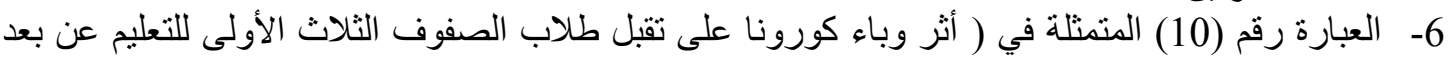

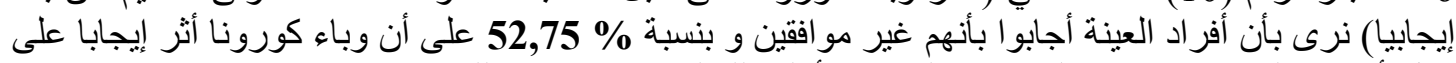

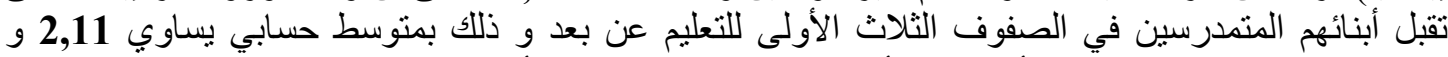
انحر اف معياري قدره 1,18 الأمر الذي أكده الاختبار T الذي بين أن هناك فروق ذاتئ ذات دلالة إحصائية في

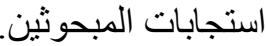

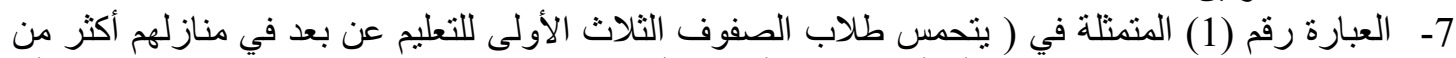

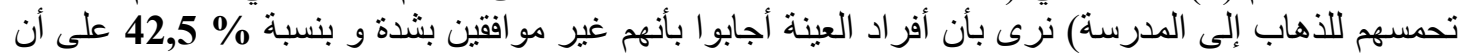

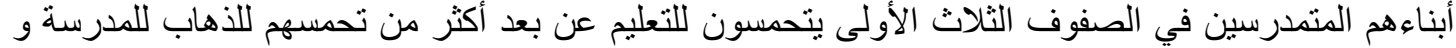
ذللك بمتوسط حسابي يساوي 1,70 و انحر اف معياري قدره 0 الأس الأمر الذي أكده الاختبار T حيث بين أن هنالك فروق ذات دلالة إحصائية في استجابات المبحوثين.

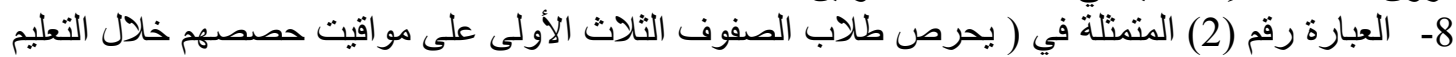

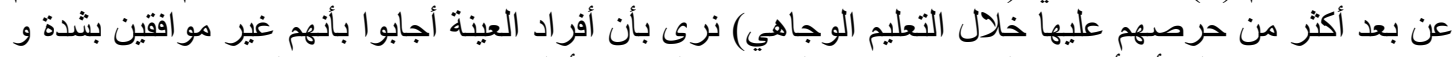

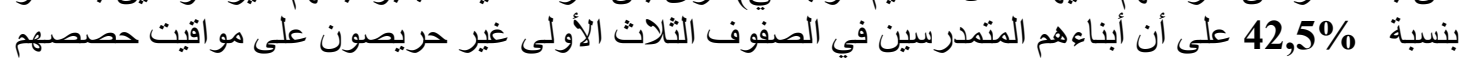




\begin{tabular}{|c|c|c|c|}
\hline 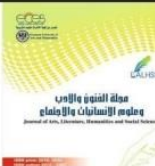 & 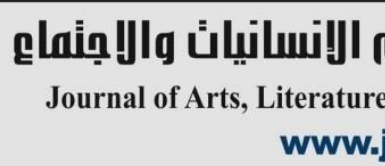 & $\begin{array}{l}\text { Illg ưgill älng } \\
\text { ies and Social Sciences } \\
\text { om }\end{array}$ & \\
\hline$=$ & Volume (70) August 2021 & العدد (70) أغسطس 2021 & \\
\hline
\end{tabular}

خلال التعليم عن بعد مقارنة بالتعليم الوجاهي و ذللك بمتوسط حسابي يساوي 1,70 و انحر اف اف معياري قدره

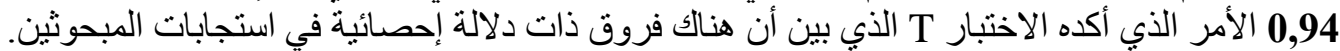

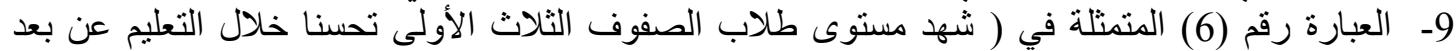

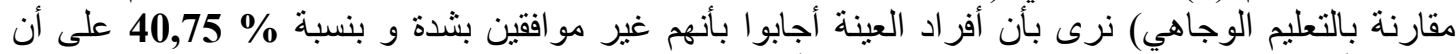

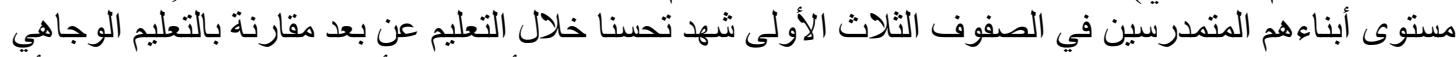
و ذللك بمتوسط حسابي يساوي 1,63 و انحر اف معياري قدره هناك دلالة إحصائية في استجابات المبحوثين.

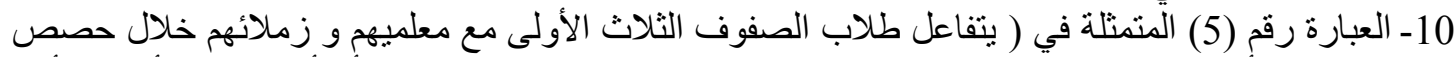

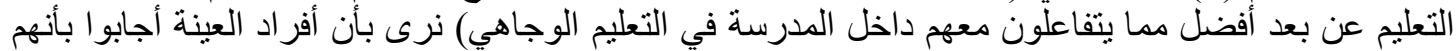
غير مو افقين بشدة و بنسبة \%

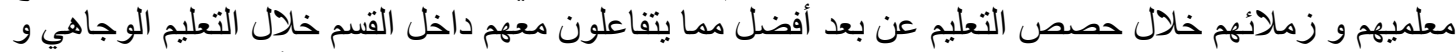

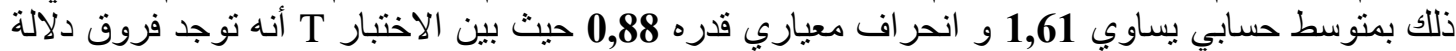
إحصائية في استجابات المبحوثين.

و من خلال هذه النتائج نجد أن العبارة يحس طلاب الصفوف الثلاث الأولى بالملل من الحصص الدر اسلية خلال

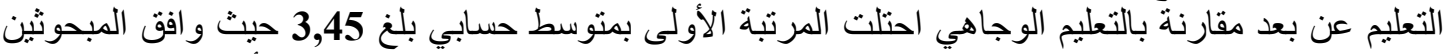

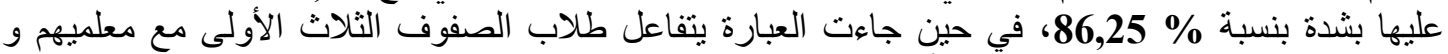

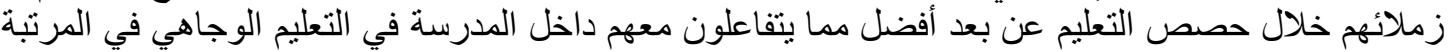
الأخيرة بمنوسط حسابي بلغ 1,61 حيث عبر المبحوثين و بنسبة 40,25\% بأنهم غير مو افقين عليها بشدة.

مناقشة النتائج:

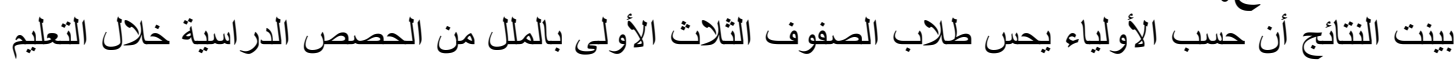

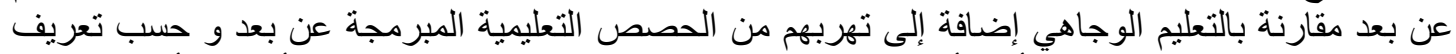

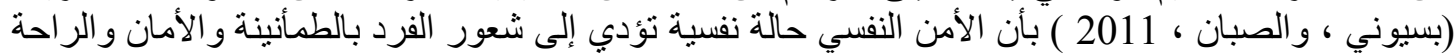

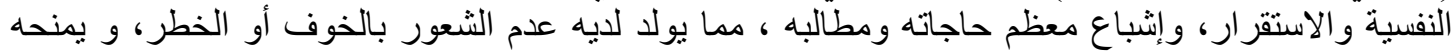

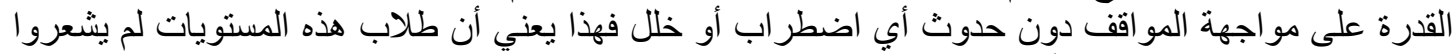

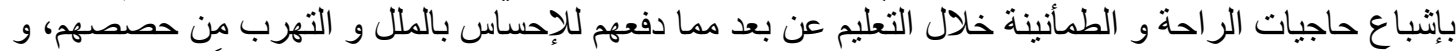

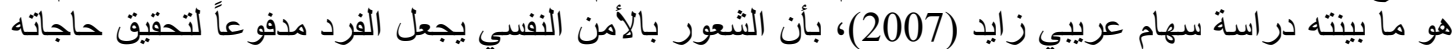

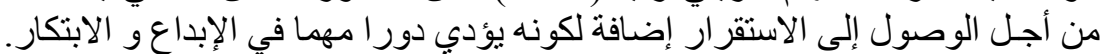

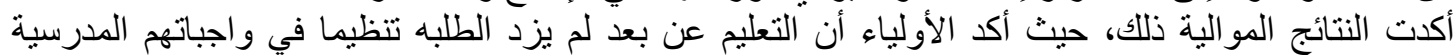

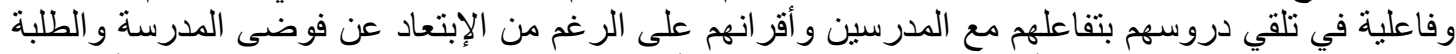

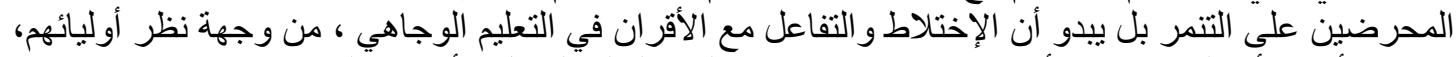

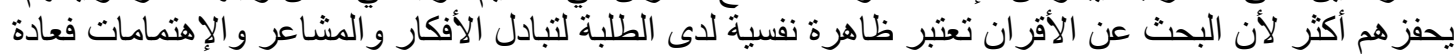

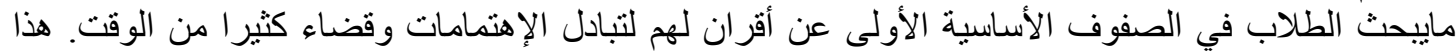

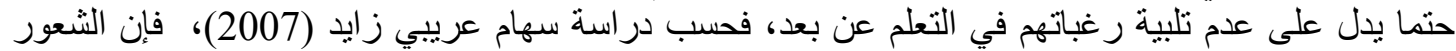

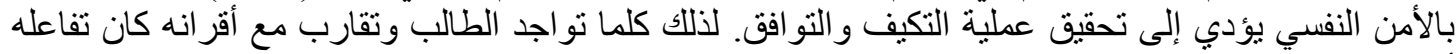

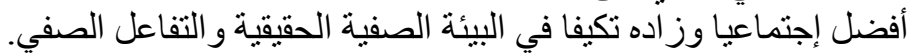

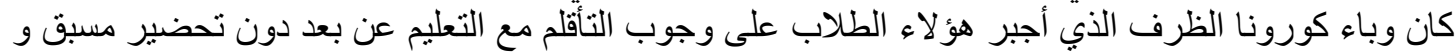

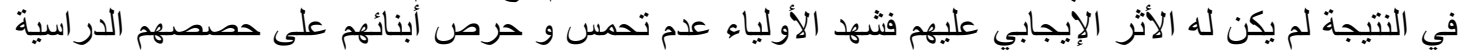

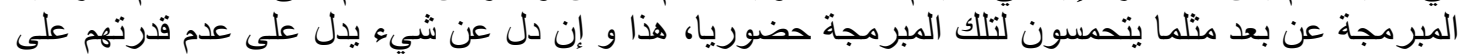

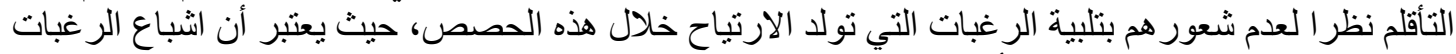

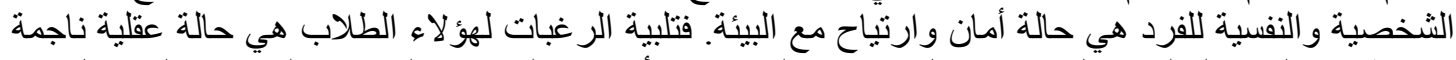

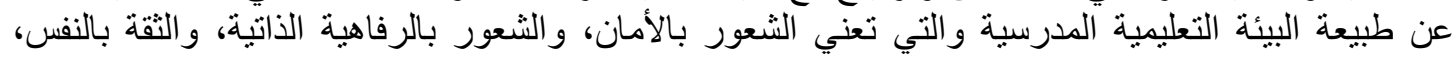

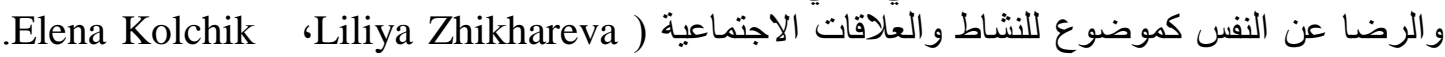




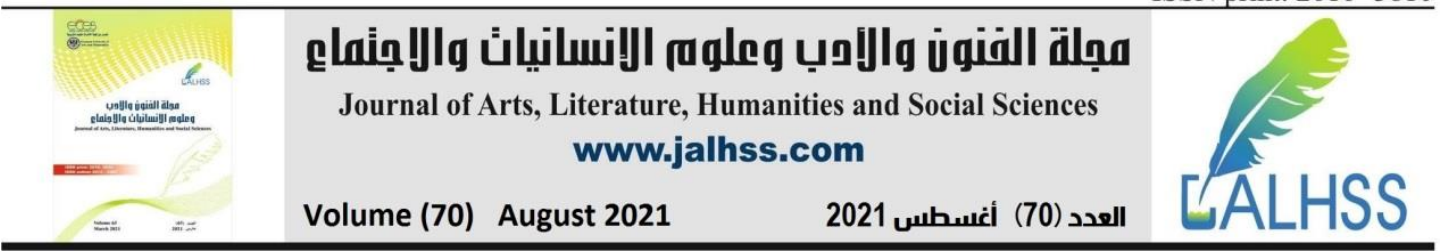

2019) و بالتالي عدم شعور هؤ لاء الطلاب بتلبية رغباتهم كأحد مرتكزات الأمن النفسي أدى حتما إلى نفور هم إنه

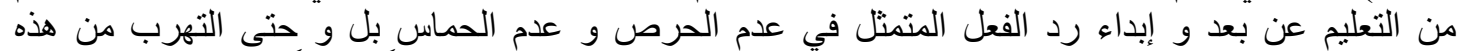

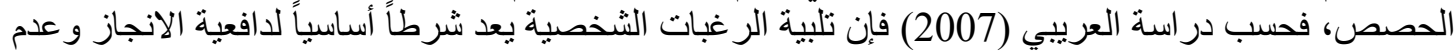

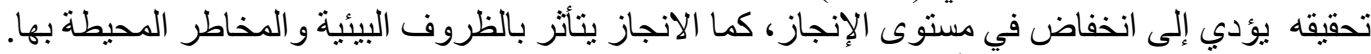

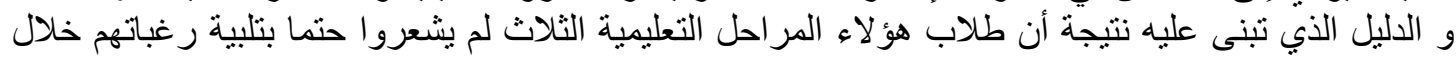

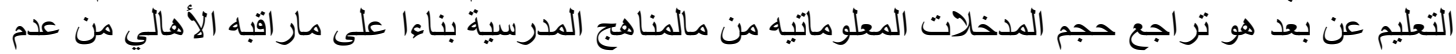

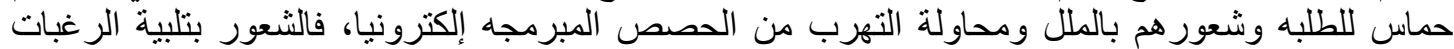

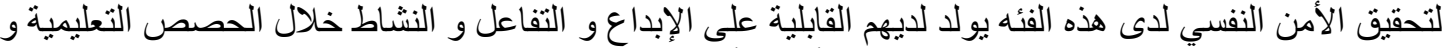
هو ما لم يُسجل خلال نمط التعليم عن بعد حسب أولياء أمور الطلبه.

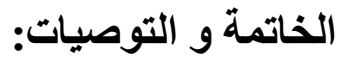

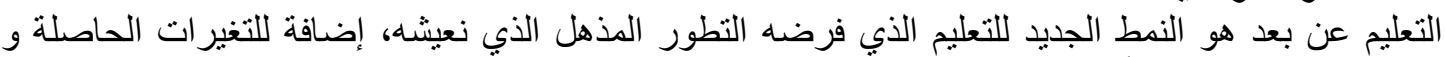

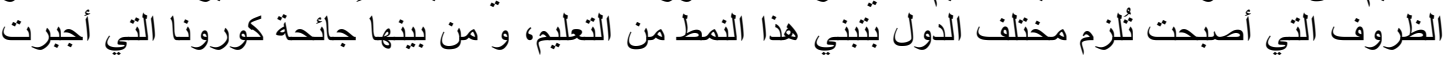

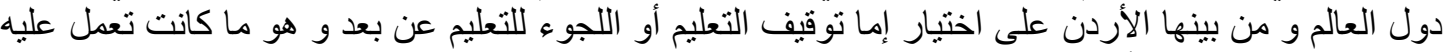

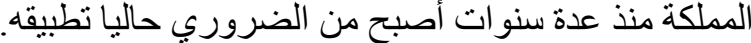

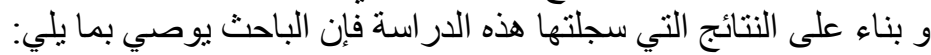

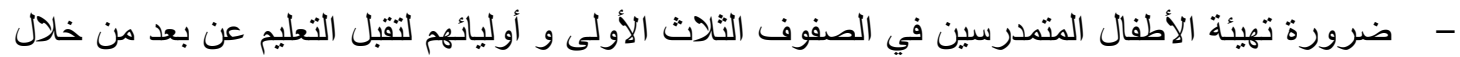

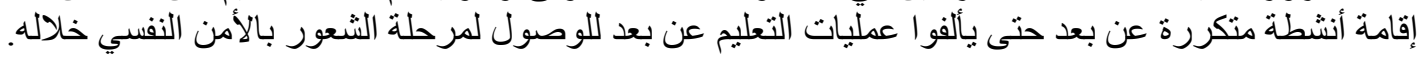

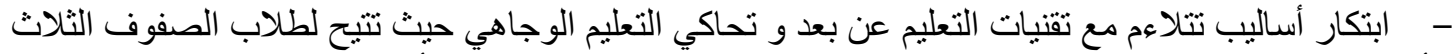

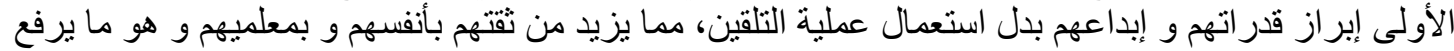

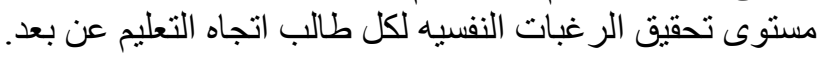

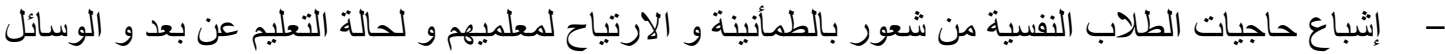

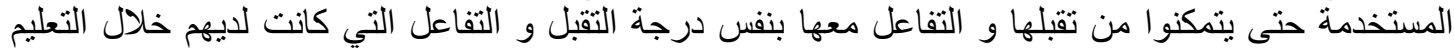

- ضرورة إجر اء المزيد من الأبحاث و الدراسات على عينات مختلفة حول هذا الموضوع. - اهتمام وزارة التربية و التعليم بتطوير الجانب النفسي لطلاب الصفوف الأولى حيال التعليم عن بعد، من خلال إثر الك متخصصين نفسانيين و علماء النفس للأطفال.

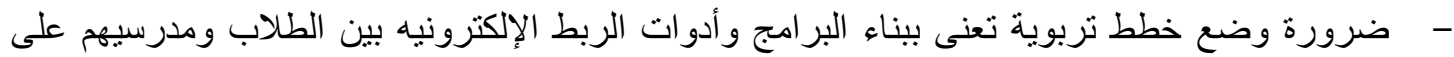

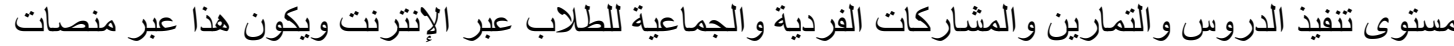

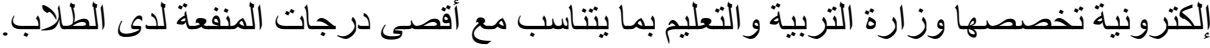

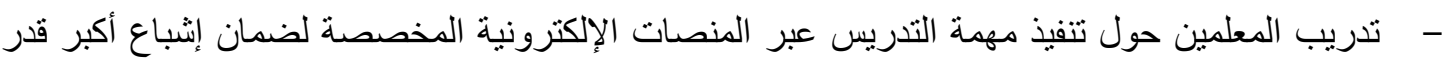

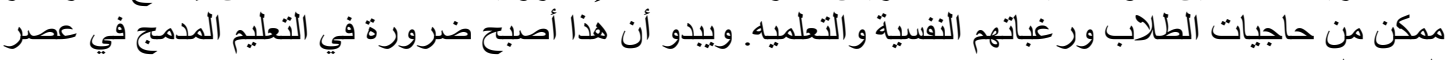

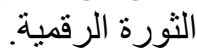

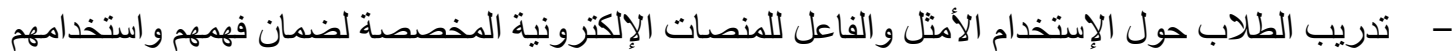
الأمثل لتحقيق رغباتهم و إز الذة أي عقبات تربوية أو نفسية أو تعلميه. 


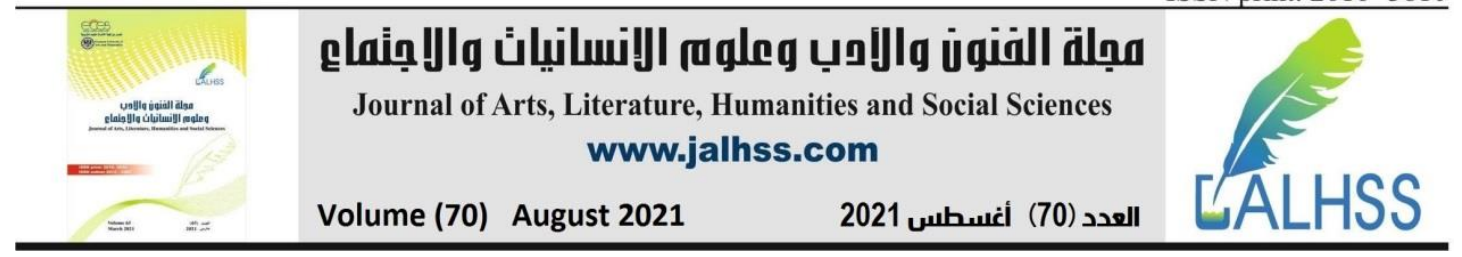

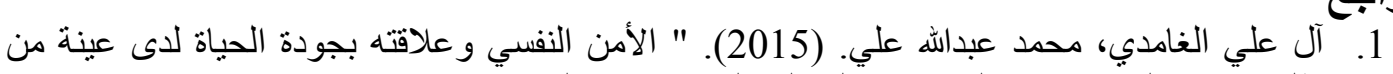

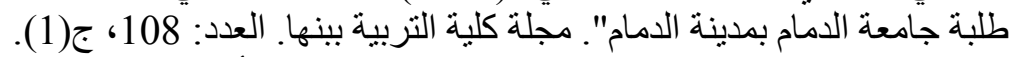

$$
\begin{aligned}
& \text { 2. عبد المجيد، السيد محمد. (2004). "إساءة المعاملة و الأمن النفسي لدى جلى عينة من تلاميذ المدرسة }
\end{aligned}
$$

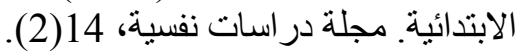

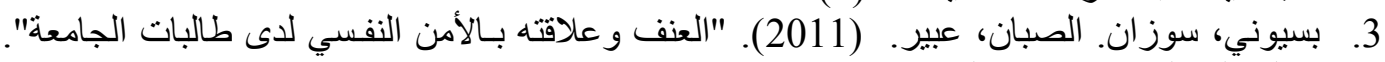

$$
\begin{aligned}
& \text { مجلة كلية التربية، جامعة المنصورة، ج2. } \\
& \text { 4. بن ساسي، عقيل. (2013). " الأمن النفسي وعلافته بالأنشطة الإبداعية لدى تلاميذ الخامسة ابتدائي }
\end{aligned}
$$

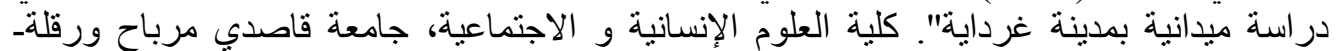

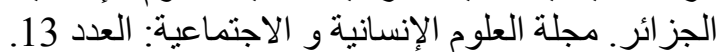

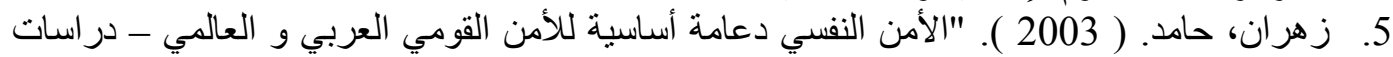

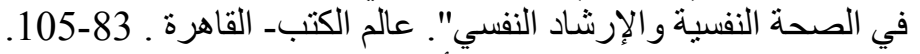

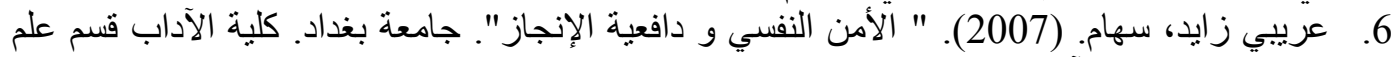

$$
\begin{aligned}
& \text { النفس. مجلة كلية الآداب، العدد: } 83 .
\end{aligned}
$$

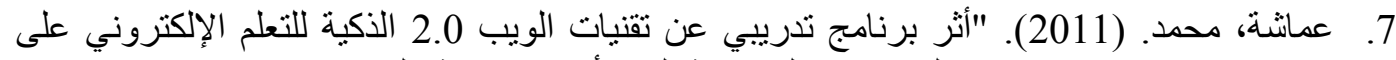

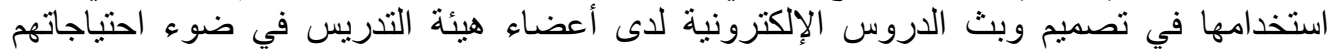

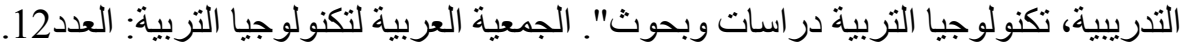

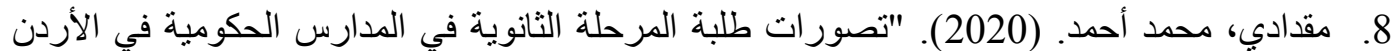

$$
\begin{aligned}
& \text { لاستخدام التعليم عن بعد في ظل أزمة كوروناومستجداتها". المجلة العربية للنشر العلمي: العدد التاسع الأسية } \\
& \text { 9. منظمة الأمم المتحدة للتربية و العلم و الثقافة. (2020). "التعليم عن بعد في العالم العربي، تقرير حول }
\end{aligned}
$$

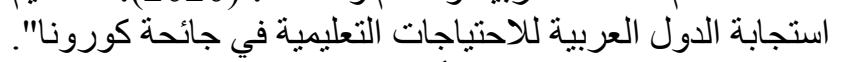

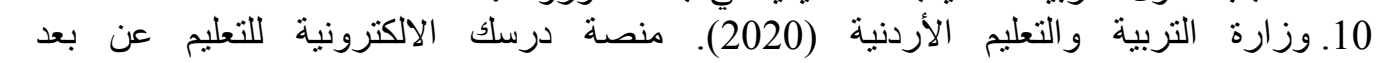

$$
\begin{aligned}
& \text { /https://www.npa7sry.com/darsak-gov-jo }
\end{aligned}
$$

11. A. Pauline Chitra, M. Antoney Raj. (2018). E-Learning. Journal of Applied and Advanced Research 3(S1):11.

12. Liliya Zhikhareva, Elena Kolchik. (2019). PSYCHOLOGICAL SAFETY OF THE PRIMARY SCHOOLCHILD IN THE EDUCATIONAL ENVIRONMENT. Future Academy. ISSN: 2357-1330. P3 .

13. Nafaa, N., and El-Tanahi, N. (2011). Effect of cardio karate on some of tension and psychological security indications and its relationship with the aspiration level to the orphans. Ovidius University Annals, Romania, Series Physical Education and Sport / SCIENCE, MOVEMENT AND HEALTH 29 code CNCSIS category B+, 11(1), 104-112

14. Prof. Indira Dhull, MS. Sakshi. 2017. Online Learning. International Education \& Research Journal [IERJ], Volume : 3, Issue : 8 (1).

15. Wahyu Irawan.Andi, Dwisona, Lestari.Mardi. (2020). "Psychological Impacts of Students on Online Learning During the Pandemic COVID-19". Universitas Mulawarman Indonesia, Universitas Tadulako Indonesia. KONSELI: Jurnal Bimbingan dan Konseling (E-Journal) : 07 (1). 53-60. 